\title{
Bending of Super-Elliptical Mindlin Plates by Finite Element Method
}

\author{
Murat ALTEKIN ${ }^{1}$
}

\begin{abstract}
Bending of shear deformable super-elliptical plates under transverse load was investigated using the Mindlin plate theory by means of the finite element method. Four-noded isoparametric quadrilateral plate bending element with three degrees of freedom per node was used. Parametric results for the maximum deflections were presented via sensitivity analysis for several geometric characteristics such as thickness, aspect ratio, and superelliptical power. Good agreement with the solutions of elliptical and rectangular plates was obtained using fine mesh. The results revealed that the deflections of clamped and point supported super-elliptical plates lie in the range bounded by elliptical and rectangular plates. However, the bending response of simply supported plates was observed to be entirely different. It was shown that high rate of convergence is required to obtain such a relation and using insufficient number of degrees of freedom results in finding a totally different trend for the clamped case.
\end{abstract}

Keywords: Plate, bending, deflection, finite element method.

\section{INTRODUCTION}

Plates are basic structural members which are used extensively in many disciplines like mechanical, civil, aerospace, and marine engineering, and in offshore structures. Because of their practical importance, the analysis of plates has always received significant interest, and thousands of studies have been published [1-12]. These studies may be categorized into various ways with regard to (i) the shape of the plate, (ii) the plate theory, (iii) the solution method, (iv) the material properties, (v) the boundary conditions, (vi) the scope of research (bending, buckling, or vibration), (vii) the type of analysis (theoretical, experimental or computational), and (viii) the classifications based on the thickness (membrane, thin, moderately thick or thick [13].

Since dealing with 2-D equations is relatively simple than 3-D equations, and 3-D equations inevitably involve numerical errors of experimental nature as well as 2-D equations do [14], the extensive literature mostly involves solutions using 2-D equations. The publications on

\section{Note:}

- This paper has been received on August 03, 2017 and accepted for publication by the Editorial Board on May 16, 2018.

- Discussions on this paper will be accepted by September 30, 2018.

- DOI: $10.18400 /$ tekderg.332384

1 Yildiz Technical University, Department of Civil Engineering, İstanbul, Turkey - altekin@yildiz.edu.tr 
plates are basically focused on the analysis of thin and moderately thick plates based on Kirchhoff and Mindlin plate theories, respectively [15-76]. These plate theories have been two of the most applied models on the analysis of plates [37]. This is partly because these theories have been widely accepted among researchers [38], and partly because these models produce results with acceptable accuracy with less computational effort in comparison with three-dimensional elasticity solutions or higher order plate theories. Since closed form solutions are only available for a limited number of cases depending on (i) the geometry of the plate, (ii) the loading, (iii) the boundary conditions, and (iv) the plate model, numerical methods have almost always been employed in the solution of plate problems.

Bending is one of the most common and important mechanical behaviors of plates, which is often crucial for safety and performance of the structures [39]. Due to their geometrical simplicity rectangular plates have been widely studied in the literature. However, from the engineering point of view, sharp corners may be critical due to stress concentrations. Besides, plates with curved boundaries have been used in many industrial applications (e.g, platforms, wings of aircrafts, components of machines).

Despite their common practical importance, there is still lack of data on plates with curved perimeters. Furthermore, notwithstanding their prevalent usage in engineering applications (e.g., slabs supported by columns, solar panels, printed circuit boards, and telescope mirrors) the investigations on point supported plates are less common than those involving simply supported or clamped boundaries owing to mathematical difficulties.

Super-elliptical plates include a large variety of plate shapes ranging from an ellipse to a rectangle with rounded corners. Unlike plates with sharp corners, rectangular plates with rounded corners enable to diffuse and dilute stress concentrations [40]. Despite the recently published papers, the studies on the analysis of super-elliptical plates have mostly been made for the dynamic behavior, and generally thin plates have been investigated [41-59]. To the best of the author's knowledge, there are only nine published papers on the bending of superelliptical plates all of which focused on thin plates only [60-68]. Thus, the current work was motivated by the lack of contributions on the bending analysis of shear deformable superelliptical plates. As far as the author knows, in the literature devoted to the bending analysis of super-elliptical plates under transverse load, this is the first study solved by the finite element method, and also the first paper in which the Mindlin plate model was used to examine simply supported, clamped, and point supported super-elliptical plates. In the current study sensitivity analysis was made to determine the influence of the thickness, the super-elliptical power, the aspect ratio, and the boundary conditions on the maximum deflection of moderately thick super-elliptical plates. Convergence studies were performed for h-refinement (i.e., more of the same kind of elements [69]), and the results were checked with the solutions of the limiting cases which are elliptical (e) and rectangular (r) plates.

\section{FORMULATION}

The boundary of the homogeneous and isotropic plate with uniform thickness is defined by

$$
\left(\frac{\mathrm{x}}{\mathrm{a}}\right)^{2 \mathrm{k}}+\left(\frac{\mathrm{y}}{\mathrm{b}}\right)^{2 \mathrm{k}}=1, \quad \mathrm{k}=1,2, \ldots, \infty
$$


As $\mathrm{k}$ is raised, the shape becomes a rectangle with rounded corners, and therefore, the area of the middle surface of the plate increases with increasing k (Fig. 1). Four-noded isoparametric quadrilateral plate bending element with straight boundaries developed by Hughes et al. (1977) [70] was used in discretiziting the plate domain. The geometry of the element is identified by [71].

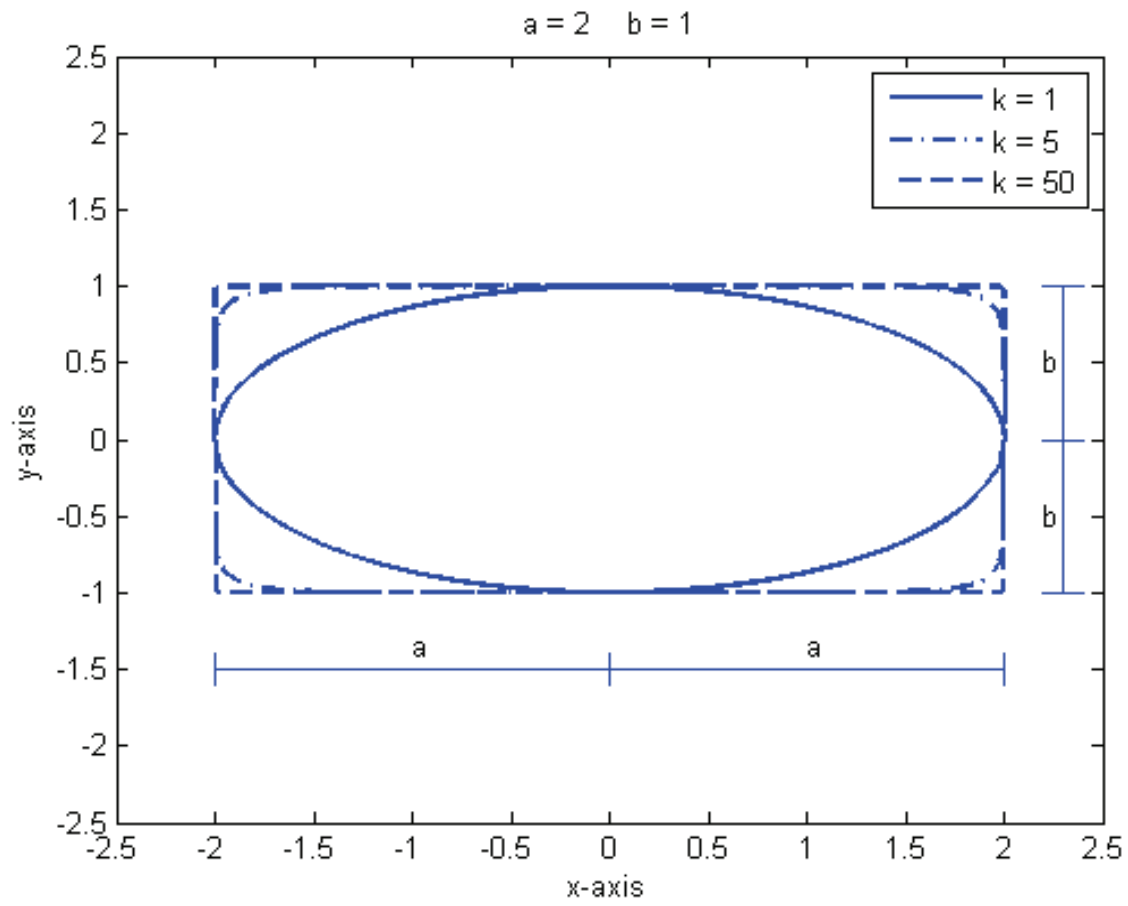

Figure 1. Geometry of a super-elliptical plate $(c=2)$

$\mathrm{x}=\sum_{\mathrm{i}=1}^{4} \mathrm{~N}_{\mathrm{i}} \mathrm{x}_{\mathrm{i}}, \quad \mathrm{y}=\sum_{\mathrm{i}=1}^{4} \mathrm{~N}_{\mathrm{i}} \mathrm{y}_{\mathrm{i}}, \quad \mathrm{N}_{\mathrm{i}}=\frac{1}{4}\left(1+\mathrm{rr}_{\mathrm{i}}\right)\left(1+\mathrm{ss}_{\mathrm{i}}\right)$

Each element has three field variables (i.e., degrees of freedom) per node. These field variables involve the deflection, and the rotations denoted by $\mathrm{w}, \theta_{\mathrm{x}}$ and $\theta_{\mathrm{y}}$, respectively.

$\mathrm{w}=\sum_{\mathrm{i}=1}^{4} \mathrm{~N}_{\mathrm{i}} \mathrm{w}_{\mathrm{i}}, \quad \theta_{\mathrm{x}}=\sum_{\mathrm{i}=1}^{4} \mathrm{~N}_{\mathrm{i}} \theta_{\mathrm{xi}}, \quad \theta_{\mathrm{y}}=\sum_{\mathrm{i}=1}^{4} \mathrm{~N}_{\mathrm{i}} \theta_{\mathrm{yi}}$

The element shape functions are bilinear for transverse displacement and rotations. $\mathrm{C}^{0}$ continuity for the displacement model was ensured based on the Mindlin's plate theory. The 
shear locking was prevented by separating the shear and bending energy terms and using selective integration procedure. The curvature and shear deformation vector $\{\varepsilon\}$ and the nodal displacement vector $\left\{\mathrm{d}_{\mathrm{i}}\right\}$ are related by [71]

$$
\begin{aligned}
& \left\{\mathrm{d}_{\mathrm{i}}\right\}^{\mathrm{T}}=\left\{\mathrm{w}_{\mathrm{i}} \quad \theta_{\mathrm{xi}} \quad \theta_{\mathrm{yi}}\right\}, \quad\{\varepsilon\}=\sum_{\mathrm{i}=1}^{4}\left[\mathrm{~B}_{\mathrm{i}}\right]\left\{\mathrm{d}_{\mathrm{i}}\right\} \\
& {\left[\mathrm{B}_{\mathrm{i}}\right]=\left[\begin{array}{ccc}
0 & 0 & \frac{\partial \mathrm{N}_{\mathrm{i}}}{\partial \mathrm{x}} \\
0 & -\frac{\partial \mathrm{N}_{\mathrm{i}}}{\partial \mathrm{y}} & 0 \\
0 & -\frac{\partial \mathrm{N}_{\mathrm{i}}}{\partial \mathrm{x}} & \frac{\partial \mathrm{N}_{\mathrm{i}}}{\partial \mathrm{y}} \\
\frac{\partial \mathrm{N}_{\mathrm{i}}}{\partial \mathrm{x}} & 0 & \mathrm{~N}_{\mathrm{i}} \\
\frac{\partial \mathrm{N}_{\mathrm{i}}}{\partial \mathrm{y}} & -\mathrm{N}_{\mathrm{i}} & 0
\end{array}\right]}
\end{aligned}
$$

The element stiffness matrix is given by

$$
\left[\mathrm{k}_{\mathrm{e}}\right]=\iint_{\mathrm{A}}[\mathrm{B}]^{\mathrm{T}}[\mathrm{C}][\mathrm{B}] \mathrm{dxdy}, \quad\left[\mathrm{k}_{\mathrm{e}}\right]=\left[\mathrm{k}_{\mathrm{B}}\right]+\left[\mathrm{k}_{\mathrm{S}}\right]
$$

where [71]

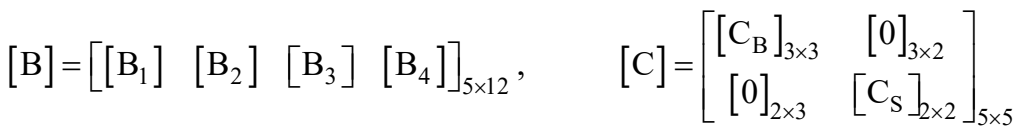

$$
\begin{aligned}
& \mathrm{D}=\frac{\mathrm{Eh}^{3}}{12\left(1-v^{2}\right)}, \quad\left[\mathrm{C}_{\mathrm{B}}\right]=\mathrm{D}\left[\begin{array}{ccc}
1 & v & 0 \\
v & 1 & 0 \\
0 & 0 & \frac{(1-v)}{2}
\end{array}\right], \quad \mathrm{G}=\frac{\mathrm{E}}{2(1+v)} \\
& {\left[\mathrm{C}_{\mathrm{S}}\right]=\mathrm{D}_{\mathrm{S}}\left[\begin{array}{ll}
1 & 0 \\
0 & 1
\end{array}\right], \quad \mathrm{D}_{\mathrm{s}}=\mathrm{Gh \kappa}}
\end{aligned}
$$


The element stiffness matrix [ $\mathrm{k}_{\mathrm{e}}$ ] shown in Eq. (6) is composed of the bending stiffness $\left[\mathrm{k}_{\mathrm{B}}\right]$ and the shear stiffness $\left[\mathrm{k}_{\mathrm{S}}\right]$ parts for which numerical integrations are performed using Gauss quadrature with $2 \times 2$ [8] and 1x1 schemes, respectively [71].

The strain-displacement matrix [B] shown in Eq. (7) is formed by the matrix $\left[\mathrm{B}_{\mathrm{i}}\right]$ where $\mathrm{i}=1,2,3,4$ such that the first three rows of $\left[\mathrm{B}_{\mathrm{i}}\right]$ relate the curvatures to displacements, and the last two rows of $\left[\mathrm{B}_{\mathrm{i}}\right]$ relate the shear deformations to displacements $[73] .\left[\mathrm{C}_{\mathrm{B}}\right]$ and $\left[\mathrm{C}_{\mathrm{S}}\right]$ are the bending and shear parts of the constitutive matrix [C] which represents rigidity.

\section{ANALYSIS}

Due to the two fold symmetry with respect to $\mathrm{x}$ and $\mathrm{y}$ axes the quarter of the plate was considered in the solution. The mesh pattern used in the paper is composed of nonuniform quadrilateral elements. The process of automatic mesh generation was executed by an algorithm which was coded in Python by the author (Fig. 2), and the figures were plotted using Matlab. Six cases including clamped (C), simply supported (S), and point-supported (PS) plates were investigated in the paper (Tables 1-2). For cases 1-2, the plate was considered to be resting on symmetrically distributed four point supports located on the plate contour and on the diagonals defined by $y= \pm(b / a) x$ such that for a large value of the super-elliptical power (such as $\mathrm{k}=200$ ) the plate approximates to a corner supported rectangular plate. The transverse displacement was prevented at the point supports each of which was modelled by a line support of length $\Delta=0.5 /(3 p)$ on the above mentioned diagonal lines.
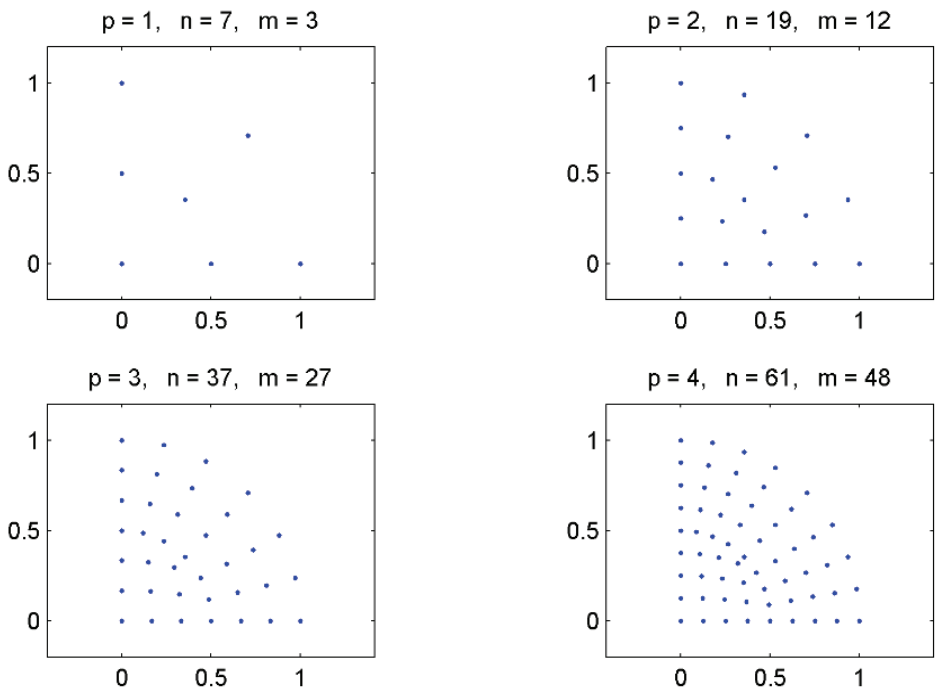

Figure 2. Location of the nodes in a quarter of the plate $(k=1, c=1)$ 
Two types of loading were considered: (i) uniformly distributed transverse pressure q, and (ii) a transverse central point load Q. The geometrical boundary conditions were satisfied exactly. The global nodal displacements were obtained by

$$
[\mathrm{K}]\{\mathrm{U}\}=\{\mathrm{F}\}
$$

The simulation was carried out using the parameters defined by

$$
\begin{aligned}
& \mathrm{c}=\frac{\mathrm{a}}{\mathrm{b}}, \quad \eta=\frac{\mathrm{h}}{\mathrm{b}}, \quad \kappa=\frac{5}{6}, \quad v=0.3, \quad \mathrm{~W}=\mathrm{w} \frac{\mathrm{D}}{\mathrm{qa}^{4}}, \quad \lambda=\mathrm{w} \frac{\mathrm{D}}{\mathrm{Qa}^{2}} \\
& \mu=\frac{\mathrm{W}_{(\mathrm{PS})}}{\mathrm{W}_{(\mathrm{C})}} \frac{1}{\mathrm{c}}, \quad \beta=\frac{\lambda_{(\mathrm{PS})}}{\lambda_{(\mathrm{C})}} \frac{1}{\mathrm{c}}, \quad \Omega=\mathrm{Wa}^{4}
\end{aligned}
$$

Table 1. Details of the numerical investigations

\begin{tabular}{|l|l|l|l|l|l|l|}
\hline Support configuration & (PS) & (PS) & (C) & (C) & (S) & (S) \\
\hline Type of loading & $\mathrm{q}$ & $\mathrm{Q}$ & $\mathrm{q}$ & $\mathrm{Q}$ & $\mathrm{q}$ & $\mathrm{Q}$ \\
\hline Case number & 1 & 2 & 3 & 4 & 5 & 6 \\
\hline
\end{tabular}

Table 2. Number of meshes and nodes in a quarter of the plate

\begin{tabular}{|l|l|l|l|}
\hline Support configuration & (PS) & $(\mathrm{C})$ & $(\mathrm{S})$ \\
\hline Case number & $1-2$ & $3-4$ & $5-6$ \\
\hline $\mathrm{m}$ & 4332 & 2028 & 2028 \\
\hline $\mathrm{n}$ & 4447 & 2107 & 2107 \\
\hline $\mathrm{p}$ & 38 & 26 & 26 \\
\hline
\end{tabular}

\section{NUMERICAL RESULTS}

Convergence studies by h-refinement showed that the use of fine mesh is required for admissable accuracy. The accuracy of the results was validated by comparing the nondimensional maximum deflection with those of elliptical, rectangular, and super-elliptical plates (Tables 3-6). Some of the results cited in Tables 3-6 were scaled by the author, and some of them were computed by the author using the formulations given in the cited references. Good agreement was obtained in the comparison tests which were made for thin and moderately thick plates.

Basic information such as the method of solution and the range of the super-elliptical power used in the previous studies on the bending of super-elliptical plates was shown in Table 7. 
Table 3. Comparison of nondimensional maximum deflection of thin elliptical and rectangular plates $(\eta=0.002)$

\begin{tabular}{|l|l|l|l|l|l|l|l|l|}
\hline & & Case 3 & Case 3 & Case 5 & Case 5 & Case 4 & Case 6 & \\
\hline & & $(\mathrm{C})$ & $(\mathrm{C})$ & $(\mathrm{S})$ & $(\mathrm{S})$ & $(\mathrm{C})$ & $(\mathrm{S})$ & \\
\hline $\mathrm{p}$ & $2 \mathrm{k}$ & $\mathrm{W}(\mathrm{c}=1)$ & $\mathrm{W}(\mathrm{c}=2)$ & $\mathrm{W}(\mathrm{c}=1)$ & $\mathrm{W}(\mathrm{c}=2)$ & $\lambda(\mathrm{c}=1)$ & $\lambda(\mathrm{c}=1)$ & Reference \\
\hline & $(\mathrm{e})$ & 0.015625 & & 0.063702 & & 0.019894 & 0.050501 & {$[27]$} \\
\hline & $(\mathrm{e})$ & 0.015625 & & 0.064103 & 0.009043 & & & {$[72]$} \\
\hline 26 & 2 & 0.0156202 & 0.00211820 & 0.0636745 & 0.0088940 & 0.0198863 & 0.0504901 & \\
\hline 25 & 2 & 0.0156198 & 0.00211820 & 0.0636723 & 0.0088937 & 0.0198855 & 0.0504891 & \\
\hline 24 & 2 & 0.0156193 & 0.00211820 & 0.0636697 & 0.0088934 & 0.0198846 & 0.0504879 & \\
\hline & $(\mathrm{r})$ & 0.02016 & & & & & 0.0464 & {$[72]$} \\
\hline & $(\mathrm{r})$ & 0.02032 & & & & & & {$[2]$} \\
\hline & $(\mathrm{r})$ & & & 0.064992 & 0.01013 & & 0.0464 & {$[27]$} \\
\hline 26 & 400 & 0.0202462 & 0.0025333 & 0.0650483 & 0.0101323 & 0.0224422 & 0.0464279 & \\
\hline 25 & 400 & 0.0202463 & 0.00253330 & 0.0650475 & 0.0101322 & 0.0224415 & 0.0464270 & \\
\hline 24 & 400 & 0.0202463 & 0.00253330 & 0.0650469 & 0.0101322 & 0.0224408 & 0.0464265 & \\
\hline
\end{tabular}

Table 4. Comparison of nondimensional maximum deflection $W$ of shear deformable elliptical and rectangular plates

\begin{tabular}{|l|l|l|l|l|l|l|l|l|}
\hline $\mathrm{p}$ & $\mathrm{c}$ & $2 \mathrm{k}$ & $\eta=0.010$ & $\eta=0.020$ & $\eta=0.050$ & $\eta=0.100$ & Reference & Case \\
\hline & 1 & $(\mathrm{e})$ & & & 0.01578 & & {$[21]$} & 3 \\
\hline & 1 & $(\mathrm{e})$ & 0.01561 & 0.01564 & 0.01578 & 0.01633 & {$[29]$} & 3 \\
\hline 26 & 1 & 2 & 0.0156271 & 0.0156485 & 0.0157985 & 0.0163341 & & 3 \\
\hline 25 & 1 & 2 & 0.0156266 & 0.0156481 & 0.0157981 & 0.0163337 & & 3 \\
\hline 24 & 1 & 2 & 0.0156262 & 0.0156476 & 0.0157976 & 0.0163332 & & 3 \\
\hline & 1 & $(\mathrm{r})$ & 0.020256 & 0.0202864 & & 0.0212368 & {$[26]$} & 3 \\
\hline 26 & 1 & 400 & 0.020256 & 0.0202865 & 0.0204978 & 0.0212373 & & 3 \\
\hline 25 & 1 & 400 & 0.0202561 & 0.0202865 & 0.0204978 & 0.0212374 & & 3 \\
\hline 24 & 1 & 400 & 0.0202561 & 0.0202866 & 0.0204979 & 0.0212375 & & 3 \\
\hline & 2 & $(\mathrm{r})$ & 0.0025339 & 0.0025366 & & 0.0026236 & {$[26]$} & 3 \\
\hline 26 & 2 & 400 & 0.0025342 & 0.0025369 & 0.0025560 & 0.0026239 & & 3 \\
\hline 25 & 2 & 400 & 0.0025342 & 0.0025369 & 0.0025560 & 0.0026239 & & 3 \\
\hline 24 & 2 & 400 & 0.0025342 & 0.0025370 & 0.0025560 & 0.0026239 & & 3 \\
\hline & 1 & $(\mathrm{e})$ & & & & 0.06442 & {$[22]$} & 5 \\
\hline 26 & 1 & 2 & 0.0636814 & 0.0637028 & 0.0638528 & 0.0643885 & & 5 \\
\hline 25 & 1 & 2 & 0.0636791 & 0.0637005 & 0.0638505 & 0.0643862 & & 5 \\
\hline 24 & 1 & 2 & 0.0636766 & 0.0636980 & 0.0638480 & 0.0643836 & & 5 \\
\hline & 1 & $(\mathrm{r})$ & & 0.06496 & & 0.06576 & {$[24]$} & 5 \\
\hline & 1 & $(\mathrm{r})$ & & 0.065031 & & 0.06584 & {$[20]$} & 5 \\
\hline
\end{tabular}


Table 4. Comparison of nondimensional maximum deflection $W$ of shear deformable elliptical and rectangular plates (continue)

\begin{tabular}{|l|l|l|l|l|l|l|l|l|}
\hline $\mathrm{p}$ & $\mathrm{c}$ & $2 \mathrm{k}$ & $\eta=0.010$ & $\eta=0.020$ & $\eta=0.050$ & $\eta=0.100$ & Reference & Case \\
\hline 26 & 1 & 400 & 0.0652761 & 0.0655787 & 0.0665933 & 0.0686209 & & 5 \\
\hline 25 & 1 & 400 & 0.0652752 & 0.0655777 & 0.0665922 & 0.0686198 & & 5 \\
\hline 24 & 1 & 400 & 0.0652743 & 0.0655766 & 0.0665909 & 0.0686184 & & 5 \\
\hline & 2 & $(\mathrm{r})$ & & 0.01013 & & 0.01020 & {$[24]$} & 5 \\
\hline 26 & 2 & 400 & 0.0101487 & 0.0101708 & 0.0102472 & 0.0104068 & & 5 \\
\hline 25 & 2 & 400 & 0.0101486 & 0.0101707 & 0.0102471 & 0.0104067 & & 5 \\
\hline 24 & 2 & 400 & 0.0101485 & 0.0101706 & 0.0102470 & 0.0104065 & & 5 \\
\hline & 1 & $(\mathrm{r})$ & & 0.40928 & & & {$[25]$} & 1 \\
\hline 38 & 1 & 400 & 0.403840 & 0.405156 & 0.410184 & 0.422200 & & 1 \\
\hline 36 & 1 & 400 & 0.403740 & 0.405052 & 0.410063 & 0.422025 & & 1 \\
\hline 34 & 1 & 400 & 0.403629 & 0.404935 & 0.409928 & 0.421832 & & 1 \\
\hline 32 & 1 & 400 & 0.403503 & 0.404804 & 0.409776 & 0.421618 & & 1 \\
\hline
\end{tabular}

Table 5. Comparison of nondimensional maximum deflection of (PS) thin super-elliptical plates $(\eta=0.002)$

\begin{tabular}{|l|l|l|l|l|l|}
\hline $\mathrm{p}$ & $\mathrm{c}$ & $2 \mathrm{k}$ & $\mathrm{W}($ Case 1$)$ & $\lambda($ Case 2$)$ & Reference \\
\hline & 1 & 2 & 0.0828 & & {$[60]$} \\
\hline & 1 & 2 & 0.0831 & 0.0564 & {$[65]$} \\
\hline & 1 & 2 & 0.084 & & {$[19]$} \\
\hline 38 & 1 & 2 & 0.0828439 & 0.0567861 & \\
\hline 36 & 1 & 2 & 0.0828088 & 0.0567855 & \\
\hline 34 & 1 & 2 & 0.0827695 & 0.0567847 & \\
\hline & 1 & 40 & 0.3739 & & {$[60]$} \\
\hline 38 & 1 & 40 & 0.372567 & 0.147073 & \\
\hline 36 & 1 & 40 & 0.372474 & 0.147074 & \\
\hline 34 & 1 & 40 & 0.372370 & 0.147076 & \\
\hline & 1 & 100 & 0.3939 & 0.1522 & {$[65]$} \\
\hline 38 & 1 & 100 & 0.392393 & 0.152677 & \\
\hline 36 & 1 & 100 & 0.392299 & 0.152680 & \\
\hline 34 & 1 & 100 & 0.392193 & 0.152683 & \\
\hline & 1 & $(\mathrm{r})$ & 0.3984 & & {$[72]$} \\
\hline & 1 & $(\mathrm{r})$ & 0.4052 & & {$[18]$} \\
\hline & 1 & $(\mathrm{r})$ & 0.40799 & 0.15654 & {$[17]$} \\
\hline & 1 & $(\mathrm{r})$ & 0.4081 & & {$[31,28]$} \\
\hline & & & & \\
\hline
\end{tabular}


Table 5. Comparison of nondimensional maximum deflection of (PS) thin super-elliptical plates $(\eta=0.002)$ (continue)

\begin{tabular}{|l|l|l|l|l|l|}
\hline $\mathrm{p}$ & $\mathrm{c}$ & $2 \mathrm{k}$ & $\mathrm{W}($ Case 1$)$ & $\lambda$ (Case 2$)$ & Reference \\
\hline & 1 & $(\mathrm{r})$ & 0.4171 & & {$[15]$} \\
\hline & 1 & $(\mathrm{r})$ & 0.4208 & & {$[16]$} \\
\hline & 1 & $(\mathrm{r})$ & & 0.15657 & {$[36]$} \\
\hline 38 & 1 & 400 & 0.402925 & 0.155642 & \\
\hline 36 & 1 & 400 & 0.402828 & 0.155645 & \\
\hline 34 & 1 & 400 & 0.402720 & 0.155649 & \\
\hline & 2 & 2 & 0.0497 & & {$[60]$} \\
\hline 38 & 2 & 2 & 0.0496860 & 0.0650117 & \\
\hline 36 & 2 & 2 & 0.0496704 & 0.0650103 & \\
\hline 34 & 2 & 2 & 0.0496531 & 0.0650088 & \\
\hline & 2 & 40 & 0.2140 & & {$[60]$} \\
\hline 38 & 2 & 40 & 0.213463 & 0.170878 & \\
\hline 36 & 2 & 40 & 0.213428 & 0.170876 & \\
\hline 34 & 2 & 40 & 0.213388 & 0.170873 & \\
\hline
\end{tabular}

Table 6. Comparison of the central deflection $\Omega$ of thin $(C)$ super-elliptical plates under $q$ $(\eta=0.002)$

\begin{tabular}{|l|l|l|l|l|l|l|l|l|}
\hline $\mathrm{c}$ & $\mathrm{d}$ & $\mathrm{k}=1$ & $\mathrm{k}=2$ & $\mathrm{k}=4$ & $\mathrm{k}=6$ & $\mathrm{k}=8$ & $\mathrm{k}=10$ & Reference \\
\hline 1 & 2 & 0.01563 & 0.01375 & 0.00696 & 0.00335 & 0.00172 & 0.00096 & {$[68]$} \\
\hline 1 & 2 & 0.01563 & 0.01375 & 0.00696 & 0.00335 & 0.00172 & 0.00096 & {$[61]$} \\
\hline 1 & 4 & 0.01563 & 0.01817 & 0.01683 & 0.01404 & 0.01129 & 0.00900 & {$[61]$} \\
\hline 1 & 6 & 0.01563 & 0.01945 & 0.02009 & 0.01991 & 0.01964 & 0.01934 & {$[61]$} \\
\hline 1 & 8 & 0.01563 & 0.01971 & 0.02027 & 0.02024 & 0.02019 & 0.02017 & {$[61]$} \\
\hline 1 & & & & & & & 0.02017 & {$[63]$} \\
\hline 1 & & & 0.01971 & 0.02027 & & & 0.02017 & {$[64]$} \\
\hline 1 & & 0.0156202 & 0.0197669 & 0.0202216 & 0.0202425 & 0.0202450 & 0.0202456 & $\mathrm{p}=26$ \\
\hline 1 & & 0.0156198 & 0.0197666 & 0.0202215 & 0.0202425 & 0.0202450 & 0.0202456 & $\mathrm{p}=25$ \\
\hline 1 & & 0.0156193 & 0.0197662 & 0.0202214 & 0.0202425 & 0.0202450 & 0.0202456 & $\mathrm{p}=24$ \\
\hline 2 & 2 & 0.03390 & 0.02783 & 0.01531 & 0.00864 & 0.00512 & 0.00319 & {$[68]$} \\
\hline 2 & 2 & 0.03390 & 0.02783 & 0.01531 & 0.00864 & 0.00512 & 0.00319 & {$[61]$} \\
\hline 2 & 4 & 0.03390 & 0.03682 & 0.03562 & 0.03198 & 0.02785 & 0.02391 & {$[61]$} \\
\hline 2 & 6 & 0.03390 & 0.03927 & 0.04073 & 0.04101 & 0.04110 & 0.04102 & {$[61]$} \\
\hline 2 & 8 & 0.03390 & 0.03973 & 0.04063 & 0.04063 & 0.04062 & 0.04064 & {$[61]$} \\
\hline 2 & & 0.03390 & 0.03973 & 0.04063 & & & 0.04064 & {$[64]$} \\
\hline 2 & & 0.0338912 & 0.039824 & 0.0404944 & 0.0405264 & 0.0405312 & 0.0405312 & $\mathrm{p}=26$ \\
\hline 2 & & 0.0338912 & 0.039824 & 0.0404944 & 0.0405264 & 0.0405312 & 0.0405312 & $\mathrm{p}=25$ \\
\hline 2 & & 0.0338912 & 0.039824 & 0.0404944 & 0.040528 & 0.0405312 & 0.0405328 & $\mathrm{p}=24$ \\
\hline 3 & 2 & 0.03835 & 0.02983 & 0.01778 & 0.01167 & 0.00813 & 0.00587 & {$[61]$} \\
\hline
\end{tabular}


Table 6. Comparison of the central deflection $\Omega$ of thin $(C)$ super-elliptical plates under $q$ $(\eta=0.002)$ (continue)

\begin{tabular}{|l|l|l|l|l|l|l|l|l|}
\hline $\mathrm{c}$ & $\mathrm{d}$ & $\mathrm{k}=1$ & $\mathrm{k}=2$ & $\mathrm{k}=4$ & $\mathrm{k}=6$ & $\mathrm{k}=8$ & $\mathrm{k}=10$ & Reference \\
\hline 3 & 4 & 0.03835 & 0.03891 & 0.03919 & 0.03747 & 0.03460 & 0.03139 & {$[61]$} \\
\hline 3 & 6 & 0.03835 & 0.04116 & 0.04251 & 0.04338 & 0.04411 & 0.04462 & {$[61]$} \\
\hline 3 & 8 & 0.03835 & 0.04157 & 0.04198 & 0.04191 & 0.04124 & 0.04189 & {$[61]$} \\
\hline 3 & & 0.0383535 & 0.0416583 & 0.0418777 & 0.0418851 & 0.0418851 & 0.0418851 & $\mathrm{p}=26$ \\
\hline 3 & & 0.0383535 & 0.0416583 & 0.0418851 & 0.0418851 & 0.0418851 & 0.0418851 & $\mathrm{p}=25$ \\
\hline 3 & & 0.0383535 & 0.0416583 & 0.0418851 & 0.0418851 & 0.0418851 & 0.0418851 & $\mathrm{p}=24$ \\
\hline
\end{tabular}

Table 7. Publications on the bending of isotropic super-elliptical plates

\begin{tabular}{|l|l|l|l|l|}
\hline Reference & k considered & Method & d & Support configuration \\
\hline$[60]$ & $1,2,3, \ldots, 19,20,300$ & Ritz & 12 & (PS) \\
\hline$[61]$ & $1,2,4,6,8,10$ & Galerkin & 8 & (C) \\
\hline$[65]$ & $1,2,3, ., 19,20,50,250$ & Ritz & 18 & (PS) \\
\hline$[62]$ & $1,2,4,6$ & New Double Side Approach & & (C) \\
\hline$[63]$ & 10 & Galerkin & 8 & (C) \\
\hline$[64]$ & $1,2,4,10$ & Ritz & 8 & (S), (C) \\
\hline$[66]$ & $1,2,3, \ldots, 19,20,50,200$ & Ritz & 8 & (PS) \\
\hline$[67]$ & $2,4,6$ & Galerkin, Double Side Approach & & (C) \\
\hline$[68]$ & $1,2,4,6,8,10$ & Ritz & 2 & (C) \\
\hline
\end{tabular}

Since the maximum deflection develops at the center of the plate, the numerical investigations for the cases presented in Table 1 regarding the nondimensional central deflection of shear deformable super-elliptical plates were made for several values of the parameter of thickness from $\eta=0.002$ to $\eta=0.100$ in Appendix A (Tables A1-A15). Each table was constructed to observe how the deflection trend -from an elliptical to a rectangular plateis affected with the shape (the shape of the plate is defined by the super-elliptical power which controls the roundness of the corner) and with the aspect ratio. The deflection trend corresponding to two types of loading was depicted in the same table (Tables A1-A15). Clamped (C), simply supported (S), and point-supported (PS) super-elliptical plates were analyzed in Tables A1-A5, A6-A10, and A11-A15, respectively. A decreasing incrementation in the nondimensional central deflection of clamped $(\mathrm{C})$ and point-supported (PS) plates with increasing super-elliptical power was identified in Tables A1-A5 and A11A15. The bending behavior of simply supported (S) super-elliptical plates was examined in Tables A6-A10, and it was shown that for $\mathrm{k}>3$ the nondimensional central deflection decreases with increasing super-elliptical power. It was detected that the deflection trend is not affected by the thickness of the plate.

\section{CONCLUSIONS}

Bending of moderately thick super-elliptical plates was examined based on the first order shear deformation theory (FSDT). The numerical simulation was made using the finite element method. Influence of the geometric properties of the plate on the maximum 
deflection was investigated via sensitivity analysis. Three support configurations were considered within the scope of the paper.

The bending results obtained for clamped super-elliptical plates under transverse uniform pressure in the current study were compared with those presented by Ceribasi et al. (2008) [61], Ceribasi (2012) [63], Zhang (2013) [64], and Altunsaray (2017) [68] (Table 7). In these publications, the trial function was constructed as the product of the basic function and a complete two dimensional polynomial function of degree d. Since the results corresponding to $\mathrm{k}>10$ have not been presented in these publications, a relation between the maximum deflection of super-elliptical plates and that of rectangular plates is not available in the literature. Relatively fewer terms in the trial function were considered in these studies, and therefore the deflection parameter in the studies $[61,68]$ was found to be decreasing for $\mathrm{c}=1$ and $\mathrm{k}>4$ (Table 6).

However, the results in the current study reveal that the central deflection of a clamped superelliptical plate lies in the range bounded by elliptical and rectangular plates as expected because the maximum deflection of a clamped square plate is larger than the central deflection of a clamped circular plate. This statement was also verified for super-elliptical plates under a transverse central point load (Tables A1-A5). Therefore, for both types of loading, $\mathrm{W}$ and $\lambda$ increase with increasing $\mathrm{k}$. It is worth noting that slight discrepancies which may possibly arise from truncation or rounding-off errors may be neglected for $\mathrm{c}=3$ (Table A4, Case 3).

However, the case is different for a simply supported super-elliptical plate (Tables A6-A10). The answer may be found in the fact that "the central deflection of the circular plate is larger than that of the corresponding square plate. This result may be attributed to the action of the reactive forces concentrated at the corners of the square plate which have the tendency to produce deflection of the plate convex upward" [72]. Therefore, based on the results of this study, it can be stated that interpolation may be used for the prediction of the deflection of clamped super-elliptical plates, but it should not be used for simply supported super-elliptical plates. The super-elliptical power corresponding to the maximum deflection increases with increasing aspect ratio. Beyond these specific value of $\mathrm{k}$ as $\mathrm{k}$ is raised, $\mathrm{W}$ and $\lambda$ decrease.

As far as the author knows there has been no published paper on point-supported shear deformable super-elliptical plates. Therefore, the accuracy of the results in the current study was validated through comparison with the results of thin plates, and good agreement was obtained (Tables 4-5). The maximum deflection of a corner-supported super-elliptical plate lies in the range bounded by elliptical and rectangular plates (Table A11-A15). Consequently, interpolation may be used. Compared to simply supported plates, the transverse displacement of corner supported plates is larger, but the difference gets smaller with decreasing superelliptical power.

The numerical simulations reveal that for the loadings and for the support configurations considered in the study, the linear bending response of (C) and (PS) super-elliptical plates is similar to each other (Figs. 3-4). 
Bending of Super-Elliptical Mindlin Plates by Finite Element Method

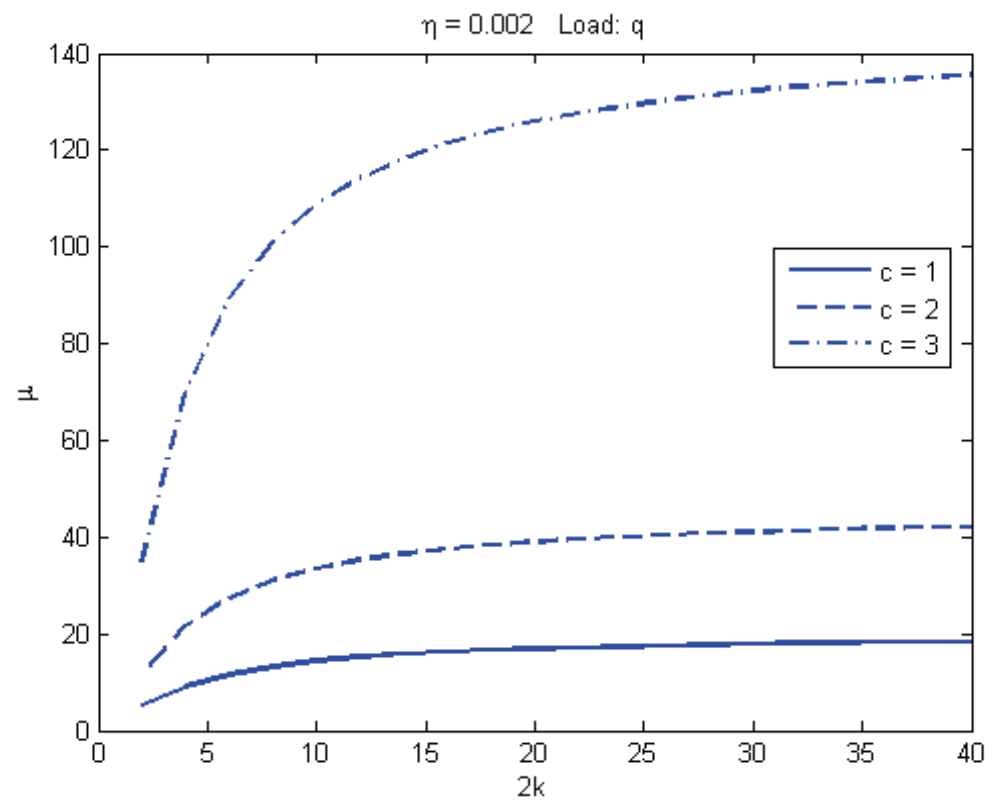

Figure 3. Bending response of $(P S)$ and $(C)$ super-elliptical plates under $q$

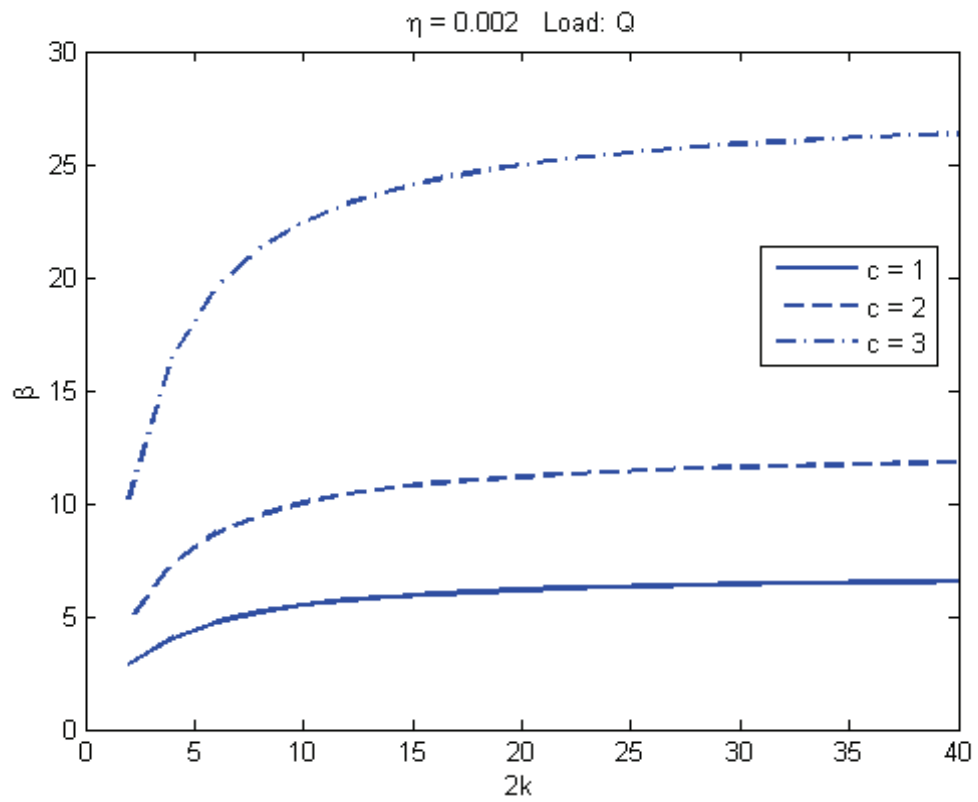

Figure 4. Bending response of (PS) and (C) super-elliptical plates under $Q$ 
It was shown that computation with high rate of convergence is required to determine the trend of the relation between the maximum deflection and the super-elliptical power (Tables 2-4). Especially for (S) and (C) plates, considering relatively fewer terms in the trial function, may lead to loss of precision due to low rate of convergence, and therefore the aforementioned trend may not be obtained with admissible accuracy.

The quadrilateral element and the mesh pattern used in the study are capable of simulating the bending response of super-elliptical plates efficiently. The boundary conditions have considerable importance on the results. The results reveal that super-elliptical plates require extensive computational effort in comparison with elliptical and rectangular plates.

\section{Symbols}
$\mathrm{a}, \mathrm{b}, \mathrm{c}$
: semi-major, and semi-minor axes of the plate, aspect ratio
d
: degree of the complete two dimensional polynomial function
$\mathrm{h}$
: thickness of the plate
$\mathrm{k}, \mathrm{m}$
: super-elliptical power, number of meshes in the quarter of the plate
$\mathrm{n}, \mathrm{p}$
: number of nodes and number of partitions in the quarter of the plate
q, w
: uniform transverse pressure, deflection
D, E, G, Q : flexural rigidity, Young's modulus, shear modulus, transverse point load
W : nondimensional deflection under uniform transverse pressure $\mathrm{q}$
$\mathrm{k}_{\mathrm{x}}, \mathrm{k}_{\mathrm{y}}, \mathrm{k}_{\mathrm{xy}} \quad$ : curvatures, twist
$\mathrm{r}_{\mathrm{i}}, \mathrm{s}_{\mathrm{i}} \quad$ : local coordinates of the $\mathrm{i}$-th node $(\mathrm{i}=1,2,3,4)$
$\mathrm{D}_{\mathrm{s}}, \mathrm{N}_{\mathrm{i}} \quad$ : shear rigidity, shape function $(\mathrm{i}=1,2,3,4)$
$\kappa, \eta, \nu \quad:$ shear correction factor, parameter of thickness, Poisson's ratio
$\theta_{\mathrm{x}}, \theta_{\mathrm{y}} \quad$ : rotations
$\lambda$
: nondimensional deflection under central point load Q
$\phi_{\mathrm{x}}, \phi_{\mathrm{y}} \quad$ : average shear deformations
$\left[\mathrm{k}_{\mathrm{e}}\right],[\mathrm{K}] \quad$ : element, and global stiffness matrices
[B], [C] : strain-displacement matrix, constitutive matrix
$\{\mathrm{F}\},\{\mathrm{U}\} \quad$ : global nodal load vector, global displacement vector
$\left[\mathrm{k}_{\mathrm{B}}\right],\left[\mathrm{k}_{\mathrm{S}}\right] \quad$ : bending, and shear stiffness part of $\left[\mathrm{k}_{\mathrm{e}}\right]$
$\left[\mathrm{C}_{\mathrm{B}}\right],\left[\mathrm{C}_{\mathrm{S}}\right]$ : bending, and shear deformation part of $[\mathrm{C}]$
$\mathrm{W}_{(\mathrm{PS})}, \mathrm{W}_{(\mathrm{C})} \quad$ : nondimensional deflection of (PS) and (C) plates under $\mathrm{q}$
$\lambda_{(\mathrm{PS})}, \lambda_{(\mathrm{C})} \quad$ : nondimensional deflection of (PS) and (C) plates under $\mathrm{Q}$
$\{\varepsilon\},\left\{\mathrm{d}_{\mathrm{i}}\right\} \quad$ : curvature and shear deformation vector, nodal displacement vector 


\section{References}

[1] Reddy, J.N., Chao, W.C., Large-deflection and large-amplitude free vibrations of laminated composite-material plates, Computers and Structures, 13 (1-3), 341-347, 1981.

[2] Mbakogu, F.C., Pavlovic, M.N., Bending of clamped orthotropic rectangular plates: a variational symbolic solution, Computers and Structures, 77 (2), 117-128, 2000.

[3] Bayer, I., Guven, U., Altay, G., A parametric study on vibrating clamped elliptical plates with variable thickness, Journal of Sound and Vibration, 254 (1), 179-188, 2002.

[4] Ozkul, T.A., Ture, U., The transition from thin plates to moderately thick plates by using finite element analysis and the shear locking problem, Thin-Walled Structures, 42 (10), 1405-1430, 2004.

[5] Setoodeh, A.R., Karami, G., Static, free vibration and buckling analysis of anisotropic thick laminated composite plates on distributed and point elastic supports using a 3-D layer-wise FEM, Engineering Structures, 26 (2), 211-220, 2004.

[6] Algazin, S.D., Vibrations of a free-edge variable-thickness plate of arbitrary shape in plan, Journal of Applied Mechanics and Technical Physics, 52 (1), 126-131, 2011.

[7] Cai, Y.C., Tian, L.G., Atluri, S.N., A simple locking-free discrete shear triangular plate element, CMES, 77 (4), 221-238, 2011.

[8] Kutlu, A., Omurtag, M.H., Large deflection bending analysis of elliptic plates on orthotropic elastic foundation with mixed finite element method, International Journal of Mechanical Sciences, 65 (1), 64-74, 2012.

[9] Sapountzakis, E.J., Dikaros, I.C., Large deflection analysis of plates stiffened by parallel beams, Engineering Structures, 35, 254-271, 2012.

[10] Thai, H.-T., Choi, D.-H., Analytical solutions of refined plate theory for bending, buckling and vibration analyses of thick plates, Applied Mathematical Modelling, 37 (18-19), 8310-8323, 2013.

[11] Rao, L.B., Rao, C.K., Buckling of annular plates with elastically restrained external and internal edges, Mechanics Based Design of Structures and Machines, 41 (2), 222-235, 2013.

[12] Sanusei, S., Mazhari, E., Shahidi, A., Analysis of buckling behavior of elliptical plate with non-concentric elliptic hole, International Journal of Materials Engineering and Technology, 13 (1), 81-108, 2015.

[13] Szilard, R., Theories and Applications of Plate Analysis, USA, John Wiley \& Sons Inc.,2004.

[14] Altay, G., Dokmeci, M.C., A polar theory for vibrations of thin elastic shells, International Journal of Solids and Structures, 43 (9), 2578-2601, 2006.

[15] Lee, S.L., Ballesteros, P., Uniformly loaded rectangular plate supported at the corners, International Journal of Mechanical Sciences, 2 (3), 206-211, 1960. 
[16] Szilard, R., Theory and Analysis of Plates, Englewood Cliffs, USA, Prentice Hall, 1974.

[17] Rajaiah, K., Rao, A.K., Collocation solution for point-supported square plates, Journal of Applied Mechanics, 45 (2), 424-425, 1978.

[18] Shanmugam, N.E., Huang, R., Yu, C.H., Lee, S.L., Uniformly loaded rhombic orthotropic plates supported at corners, Computers \& Structures, 30 (5), 1037-1045, 1988.

[19] Nong, L., Bao-lian, F., The symmetrical bending of an elastic circular plate supported at K internal points, Applied Mathematics and Mechanics, 12 (11), 1091-1096, 1991.

[20] Liew, K.M., Han, J.B., Bending analysis of simply supported shear deformable skew plates, Journal of Engineering Mechanics, 123 (3), 214-221, 1997.

[21] Han, J.B., Liew, K.M., An eight-node curvilinear differential quadrature formulation for Reissner/Mindlin plates, Computer Methods in Applied Mechanics and Engineering, 141 (3-4), 265-280, 1997a.

[22] Han, J.B., Liew, K.M., Analysis of moderately thick circular plates using differential quadrature method, Computer Methods in Applied Mechanics and Engineering, 123 (12), 1247-1252, $1997 \mathrm{~b}$.

[23] Wang, C.M., Lim, G.T., Bending solutions of sectorial Mindlin plates from Kirchhoff plates, Journal of Engineering Mechanics, 126 (4), 367-372, 2000.

[24] Wang, C.M., Lim, G.T., Reddy, J.N., Lee, K.H., Relationships between bending solutions of Reissner and Mindlin plate theories, Engineering Structures, 23 (7), 838849, 2001.

[25] Wang, C.M., Wang, Y.C., Reddy, J.N., Problems and remedy for the Ritz method in determining stress resultants of corner supported rectangular plates, Computers and Structures, 80 (2), 145-154, 2002.

[26] Lim, G.T., Reddy, J.N., On canonical bending relationships for plates, International Journal of Solids and Structures, 40 (12), 3039-3067, 2003.

[27] Reddy, J.N., Theory and Analysis of Elastic Plates and Shells, Second Edition, Boca Raton, CRC Press, 2007.

[28] Lim, C.W., Yao, W.A., Cui, S., Benchmark symplectic solutions for bending of cornersupported rectangular thin plates, The IES Journal Part A: Civil \& Structural Engineering, 1 (2), 106-115, 2008.

[29] Civalek, O., Ersoy, H., Free vibration and bending analysis of circular Mindlin plates using singular convolution method, Communications in Numerical Methods in Engineering, 25 (8), 907-922, 2009.

[30] Batista, M., An elementary derivation of basic equations of the Reissner and Mindlin plate theories, Engineering Structures, 32 (3), 906-909, 2010a. 
[31] Batista, M., New analytical solution for bending problem of uniformly loaded rectangular plate supported on corners, The IES Journal Part A: Civil \& Structural Engineering, 3 (2), 75-84, $2010 \mathrm{~b}$.

[32] Nguyen-Xuan, H., Tran, L.V., Thai, C.H., Nguyen-Thoi, T., Analysis of functionally graded plates by an efficient finite element method with node-based strain smoothing, Thin-Walled Structures, 54, 1-18, 2012.

[33] Asemi, K., Ashrafi, H., Salehi, M., Shariyat, M., Three-dimensional static and dynamic analysis of functionally graded elliptical plates, employing graded finite elements, Acta Mechanica, 224 (8), 1849-1864, 2013.

[34] Wang, C. Y., Vibrations of completely free rounded rectangular plates, Journal of Vibration and Acoustics, 137 (2), doi:10.1115/1.4029159, 2015a.

[35] Wang, C. Y., Vibrations of completely free rounded regular polygonal plates, International Journal of Acoustics and Vibration, 20 (2), 107-112, $2015 \mathrm{~b}$.

[36] Li, R., Wang, P., Tian, Y., Wang, B., Li, G., A unified analytic solution approach to static bending and free vibration problems of rectangular thin plates, Scientific Reports DOI: $10.1038 /$ srep17054, 2016.

[37] Falsone, G., Settineri, D., A Kirchhoff-like solution for the Mindlin plate model: A new finite element Approach, Mechanics Research Communications, 40, 1- 10, 2012.

[38] Endo, M., Study on an alternative deformation concept for the Timoshenko beam and Mindlin plate models, International Journal of Engineering Science, 87, 32-46, 2015.

[39] Li, R., Wang, B., Li G., Benchmark bending solutions of rectangular thin plates pointsupported at two adjacent corners, Applied Mathematics Letters, 40, 53-58, 2015.

[40] Liew, K.M., Kitipornchai, S., Lim, C.W., Free vibration analysis of thick superelliptical plates, Journal of Engineering Mechanics, 124 (2), 137-145, 1998.

[41] DeCapua, N.J., Sun, B.C., Transverse vibration of a class of orthotropic plates, Journal of Applied Mechanics, 39 (2), 613-615, 1972.

[42] Irie, T., Yamada, G., Sonoda, M., Natural frequencies of square membrane and square plate with rounded corners, Journal of Sound and Vibration, 86 (3), 442-448, 1983.

[43] Wang, C.M., Wang, L., Vibration and buckling of super elliptical plates. Journal of Sound and Vibration, 171 (3), 301-314, 1994.

[44] Lim, C.W., Liew, K.M., Vibrations of perforated plates with rounded corners, Journal of Engineering Mechanics, 121 (2), 203-213, 1995.

[45] Lim, C.W., Kitipornchai, S., Liew, K.M., A free-vibration analysis of doubly connected super-elliptical laminated composite plates, Composites Science and Technology, 58 (3-4), 435-445, 1998.

[46] Chen, C.C., Lim, C.W., Kitipornchai, S., Liew, K.M., Vibration of symmetrically laminated thick super elliptical plates, Journal of Sound and Vibration, 220 (4), 659$682,1999$. 
[47] Chen, C.C., Kitipornchai, S.,Free vibration of symmetrically laminated thick perforated plates, Journal of Sound and Vibration, 230 (1), 111-132, 2000.

[48] Liew, K.M., Feng, Z.C., Three-dimensional free vibration analysis of perforated superelliptical plates via the p-Ritz method, International Journal of Mechanical Sciences, 43 (11), 2613-2630, 2001.

[49] Zhou, D., Lo, S.H., Cheung, Y.K., Au, F.T.K., 3-D vibration analysis of generalized super elliptical plates using Chebyshev-Ritz method, International Journal of Solids and Structures, 41 (16-17), 4697-4712, 2004.

[50] Wu, L., Liu, J., Free vibration analysis of arbitrary shaped thick plates by differential cubature method. International Journal of Mechanical Sciences, 47 (1), 63-81, 2005.

[51] Altekin, M., Free linear vibration and buckling of super-elliptical plates resting on symmetrically distributed point-supports on the diagonals, Thin-Walled Structures, 46 (10), 1066-1086, 2008.

[52] Altekin, M., Free vibration of orthotropic super-elliptical plates on intermediate supports, Nuclear Engineering and Design, 239 (6), 981-999, 2009.

[53] Altekin, M., Free in-plane vibration of super-elliptical plates, Shock and Vibration, 18 (3), 471-484, 2010b.

[54] Altekin, M., Free transverse vibration of shear deformable super-elliptical plates, Wind and Structures, 24 (4), 307-331, 2017.

[55] Ceribasi, S., Altay, G., Free vibration of super elliptical plates with constant and variable thickness by Ritz method, Journal of Sound and Vibration, 319 (1-2), 668-680, 2009.

[56] Jazi, S.R., Farhatnia, F., Buckling analysis of functionally graded super elliptical plate using pb-2 Ritz method, Advanced Materials Research, 383-390, 5387-5391, 2012.

[57] Zhang, D.G., Zhou, H.M., Nonlinear symmetric free vibration analysis of super elliptical isotropic thin plates, CMC: Computers, Materials \& Continua, 40 (1), 21-34, 2014. (the author does not have access to this paper)

[58] Hasheminejad, S.M., Keshvari, M.M., Ashory, M.R., Dynamic stability of super elliptical plates resting on elastic foundations under periodic in-plane loads, Journal of Engineering Mechanics, 140 (1), 172-181, 2014.

[59] Ghaheri, A., Nosier, A., Keshmiri, A., Parametric stability of symmetrically laminated composite super-elliptical plates, Journal of Composite Materials DOI: 10.1177/0021998316629481, 2016.

[60] Altekin, M., Altay, G., Static analysis of point-supported super-elliptical plates, Archive of Applied Mechanics, 78 (4), 259-266, 2008.

[61] Ceribasi, S., Altay, G., Dökmeci, M.C., Static analysis of super elliptical clamped plates by Galerkin's method, Thin-Walled Structures, 46 (2), 122-127, 2008. 
[62] Tang, H.W., Yang, Y.T., Chen, C.K., Application of new double side approach method to the solution of super-elliptical plate problems, Acta Mechanica, 223 (4), 745-753, 2012.

[63] Ceribasi, S., Static and dynamic analysis of thin uniformly loaded super elliptical FGM plates, Mechanics of Advanced Materials and Structures, 19 (5), 325-335, 2012.

[64] Zhang, D.G., Non-linear bending analysis of super-elliptical thin plates, International Journal of Non-Linear Mechanics, 55, 180-185, 2013.

[65] Altekin, M., Bending of orthotropic super-elliptical plates on intermediate point supports, Ocean Engineering, 37 (11-12), 1048-1060, $2010 \mathrm{a}$.

[66] Altekin, M., Large deflection analysis of point supported super-elliptical plates, Structural Engineering and Mechanics, 51 (2), 333-347, 2014.

[67] Tang, H.W., Lo, C.Y., Application of double side approach method on super elliptical Winkler plate, International Journal of Mechanical, Aerospace, Industrial, Mechatronic and Manufacturing Engineering, 8 (8), 1472-1476, 2014.

[68] Altunsaray, E., Static deflections of symmetrically laminated quasi-isotropic superelliptical thin plates, Ocean Engineering, 141, 337-350, 2017.

[69] Reddy, J.N., An Introduction to the Finite Element Method, Second Edition, Singapore, McGraw-Hill International editions, 1993.

[70] Hughes, T.J.R., Taylor, R.L., Kanoknukulchai, W., A simple and efficient finite element for plate bending, International Journal for Numerical Methods in Engineering, 11 (10), 1529-1543, 1977.

[71] Krishnamoorthy, C.S., Finite Element Analysis: Theory and Programming, (Second Edition), New Delhi, Tata McGraw-Hill Publishing Company Limited, 1994.

[72] Timoshenko, S. P., Woinowsky-Krieger, S., Theory of Plates and Shells, Singapore, McGraw-Hill International Editions, 1959.

[73] Ozgan, K., Daloglu, A.T., Shear locking free finite elements for thick plates on elastic foundations, Teknik Dergi/Technical Journal of Turkish Chamber of Civil Engineers, 22 (107), 5341-5358, 2011 (in Turkish).

[74] Kumbasar, N., A generalized finite difference method for plates and rotational shells using Betti's theorem, Teknik Dergi/Technical Journal of Turkish Chamber of Civil Engineers, 28 (4), 8129-8142, 2017 (in Turkish).

[75] Aksoylar, C., Omurtag, M.H., Mixed finite element analysis of composite plates under blast loading, Teknik Dergi/Technical Journal of Turkish Chamber of Civil Engineers, 22 (109), 5689-5711, 2011 (in Turkish).

[76] Karasin, A.H., Gulkan, P. An approximate finite grid solution for plates on elastic foundations, Teknik Dergi/Technical Journal of Turkish Chamber of Civil Engineers, 19 (93), 4445-4454, 2008 (in Turkish). 


\section{Appendix A}

Table A1. Nondimensional central deflection of $(C)$ super-elliptical plates $(p=26, \eta=0.002)$

\begin{tabular}{|l|l|l|l|l|l|l|}
\hline & $\mathrm{W}$ & $\mathrm{W}$ & $\mathrm{W}$ & $\lambda$ & $\lambda$ & $\lambda$ \\
\hline $2 \mathrm{k}$ & $\mathrm{c}=1$ & $\mathrm{c}=2$ & $\mathrm{c}=3$ & $\mathrm{c}=1$ & $\mathrm{c}=2$ & $\mathrm{c}=3$ \\
\hline 2 & 0.0156202 & 0.0021182 & 0.0004735 & 0.0198863 & 0.0068442 & 0.0031454 \\
\hline 4 & 0.0197669 & 0.002489 & 0.0005143 & 0.0222393 & 0.0072021 & 0.0032137 \\
\hline 6 & 0.0201555 & 0.0025246 & 0.0005168 & 0.0224094 & 0.0072232 & 0.0032157 \\
\hline 8 & 0.0202216 & 0.0025309 & 0.0005170 & 0.0224342 & 0.007226 & 0.0032159 \\
\hline 10 & 0.0202377 & 0.0025324 & 0.0005171 & 0.0224396 & 0.0072265 & 0.0032159 \\
\hline 12 & 0.0202425 & 0.0025329 & 0.0005171 & 0.0224411 & 0.0072267 & 0.0032159 \\
\hline 14 & 0.0202443 & 0.0025331 & 0.0005171 & 0.0224416 & 0.0072267 & 0.0032159 \\
\hline 16 & 0.020245 & 0.0025332 & 0.0005171 & 0.0224418 & 0.0072267 & 0.0032159 \\
\hline 18 & 0.0202454 & 0.0025332 & 0.0005171 & 0.0224419 & 0.0072267 & 0.0032159 \\
\hline 20 & 0.0202456 & 0.0025332 & 0.0005171 & 0.0224419 & 0.0072267 & 0.0032159 \\
\hline 22 & 0.0202457 & 0.0025332 & 0.0005171 & 0.0224419 & 0.0072267 & 0.0032159 \\
\hline 24 & 0.0202457 & 0.0025332 & 0.0005171 & 0.022442 & 0.0072267 & 0.0032159 \\
\hline 26 & 0.0202458 & 0.0025332 & 0.0005171 & 0.022442 & 0.0072267 & 0.0032159 \\
\hline 28 & 0.0202458 & 0.0025332 & 0.0005171 & 0.022442 & 0.0072267 & 0.0032159 \\
\hline 30 & 0.0202458 & 0.0025332 & 0.0005171 & 0.022442 & 0.0072267 & 0.0032159 \\
\hline 32 & 0.0202459 & 0.0025333 & 0.0005171 & 0.022442 & 0.0072267 & 0.0032159 \\
\hline 34 & 0.0202459 & 0.0025333 & 0.0005171 & 0.022442 & 0.0072267 & 0.0032159 \\
\hline 36 & 0.0202459 & 0.0025333 & 0.0005171 & 0.022442 & 0.0072267 & 0.0032159 \\
\hline 38 & 0.0202459 & 0.0025333 & 0.0005171 & 0.022442 & 0.0072267 & 0.0032159 \\
\hline 40 & 0.020246 & 0.0025333 & 0.0005171 & 0.022442 & 0.0072267 & 0.0032159 \\
\hline 100 & 0.0202461 & 0.0025333 & 0.0005171 & 0.0224421 & 0.0072268 & 0.0032159 \\
\hline 400 & 0.0202462 & 0.0025333 & 0.0005171 & 0.0224422 & 0.0072268 & 0.0032159 \\
\hline & & & & & & \\
\hline
\end{tabular}

Table A2. Nondimensional central deflection of $(C)$ super-elliptical plates $(p=26, \eta=0.010)$

\begin{tabular}{|l|l|l|l|l|l|l|}
\hline & $\mathrm{W}$ & $\mathrm{W}$ & $\mathrm{W}$ & $\lambda$ & $\lambda$ & $\lambda$ \\
\hline $2 \mathrm{k}$ & $\mathrm{c}=1$ & $\mathrm{c}=2$ & $\mathrm{c}=3$ & $\mathrm{c}=1$ & $\mathrm{c}=2$ & $\mathrm{c}=3$ \\
\hline 2 & 0.0156271 & 0.002119 & 0.0004736 & 0.0199322 & 0.0068554 & 0.0031502 \\
\hline 4 & 0.0197758 & 0.0024899 & 0.0005145 & 0.0222873 & 0.0072138 & 0.0032187 \\
\hline 6 & 0.0201651 & 0.0025255 & 0.0005169 & 0.0224581 & 0.007235 & 0.0032207 \\
\hline 8 & 0.0202314 & 0.0025318 & 0.0005172 & 0.0224833 & 0.0072378 & 0.0032209 \\
\hline 10 & 0.0202475 & 0.0025333 & 0.0005173 & 0.0224888 & 0.0072384 & 0.0032209 \\
\hline 12 & 0.0202524 & 0.0025338 & 0.0005173 & 0.0224904 & 0.0072385 & 0.0032209 \\
\hline 14 & 0.0202541 & 0.002534 & 0.0005173 & 0.022491 & 0.0072386 & 0.0032209 \\
\hline 16 & 0.0202549 & 0.002534 & 0.0005173 & 0.0224912 & 0.0072386 & 0.0032209 \\
\hline 18 & 0.0202552 & 0.0025341 & 0.0005173 & 0.0224914 & 0.0072386 & 0.0032209 \\
\hline 20 & 0.0202554 & 0.0025341 & 0.0005173 & 0.0224914 & 0.0072386 & 0.0032209 \\
\hline
\end{tabular}


Table A2. Nondimensional central deflection of $(C)$ super-elliptical plates $(p=26, \eta=0.010)$ (continue)

\begin{tabular}{|l|l|l|l|l|l|l|}
\hline & $\mathrm{W}$ & $\mathrm{W}$ & $\mathrm{W}$ & $\lambda$ & $\lambda$ & $\lambda$ \\
\hline $2 \mathrm{k}$ & $\mathrm{c}=1$ & $\mathrm{c}=2$ & $\mathrm{c}=3$ & $\mathrm{c}=1$ & $\mathrm{c}=2$ & $\mathrm{c}=3$ \\
\hline 22 & 0.0202555 & 0.0025341 & 0.0005173 & 0.0224915 & 0.0072386 & 0.0032209 \\
\hline 24 & 0.0202556 & 0.0025341 & 0.0005173 & 0.0224915 & 0.0072386 & 0.0032209 \\
\hline 26 & 0.0202556 & 0.0025341 & 0.0005173 & 0.0224916 & 0.0072386 & 0.0032209 \\
\hline 28 & 0.0202557 & 0.0025341 & 0.0005173 & 0.0224916 & 0.0072386 & 0.0032209 \\
\hline 30 & 0.0202557 & 0.0025341 & 0.0005173 & 0.0224916 & 0.0072386 & 0.0032209 \\
\hline 32 & 0.0202557 & 0.0025341 & 0.0005173 & 0.0224916 & 0.0072387 & 0.0032209 \\
\hline 34 & 0.0202557 & 0.0025341 & 0.0005173 & 0.0224916 & 0.0072387 & 0.0032209 \\
\hline 36 & 0.0202557 & 0.0025341 & 0.0005173 & 0.0224917 & 0.0072387 & 0.0032209 \\
\hline 38 & 0.0202558 & 0.0025341 & 0.0005173 & 0.0224917 & 0.0072387 & 0.0032209 \\
\hline 40 & 0.0202558 & 0.0025341 & 0.0005173 & 0.0224917 & 0.0072387 & 0.0032209 \\
\hline 100 & 0.0202559 & 0.0025342 & 0.0005173 & 0.0224918 & 0.0072387 & 0.0032209 \\
\hline 400 & 0.020256 & 0.0025342 & 0.0005173 & 0.0224919 & 0.0072387 & 0.0032209 \\
\hline
\end{tabular}

Table A3. Nondimensional central deflection of $(C)$ super-elliptical plates $(p=26, \eta=0.020)$

\begin{tabular}{|l|l|l|l|l|l|l|}
\hline & $\mathrm{W}$ & $\mathrm{W}$ & $\mathrm{W}$ & $\lambda$ & $\lambda$ & $\lambda$ \\
\hline $2 \mathrm{k}$ & $\mathrm{c}=1$ & $\mathrm{c}=2$ & $\mathrm{c}=3$ & $\mathrm{c}=1$ & $\mathrm{c}=2$ & $\mathrm{c}=3$ \\
\hline 2 & 0.0156485 & 0.0021213 & 0.0004741 & 0.0200758 & 0.0068904 & 0.0031651 \\
\hline 4 & 0.0198036 & 0.0024925 & 0.0005150 & 0.0224373 & 0.007250 & 0.0032341 \\
\hline 6 & 0.0201946 & 0.0025282 & 0.0005175 & 0.0226103 & 0.0072716 & 0.0032363 \\
\hline 8 & 0.0202615 & 0.0025345 & 0.0005178 & 0.0226363 & 0.0072745 & 0.0032365 \\
\hline 10 & 0.0202778 & 0.002536 & 0.0005178 & 0.0226423 & 0.0072752 & 0.0032366 \\
\hline 12 & 0.0202828 & 0.0025365 & 0.0005178 & 0.0226442 & 0.0072754 & 0.0032366 \\
\hline 14 & 0.0202846 & 0.0025367 & 0.0005178 & 0.022645 & 0.0072755 & 0.0032366 \\
\hline 16 & 0.0202853 & 0.0025368 & 0.0005178 & 0.0226454 & 0.0072756 & 0.0032366 \\
\hline 18 & 0.0202857 & 0.0025368 & 0.0005178 & 0.0226457 & 0.0072756 & 0.0032366 \\
\hline 20 & 0.0202859 & 0.0025368 & 0.0005178 & 0.0226458 & 0.0072756 & 0.0032366 \\
\hline 22 & 0.020286 & 0.0025369 & 0.0005178 & 0.022646 & 0.0072756 & 0.0032367 \\
\hline 24 & 0.020286 & 0.0025369 & 0.0005178 & 0.0226461 & 0.0072757 & 0.0032367 \\
\hline 26 & 0.0202861 & 0.0025369 & 0.0005178 & 0.0226461 & 0.0072757 & 0.0032367 \\
\hline 28 & 0.0202861 & 0.0025369 & 0.0005178 & 0.0226462 & 0.0072757 & 0.0032367 \\
\hline 30 & 0.0202862 & 0.0025369 & 0.0005178 & 0.0226463 & 0.0072757 & 0.0032367 \\
\hline 32 & 0.0202862 & 0.0025369 & 0.0005178 & 0.0226463 & 0.0072757 & 0.0032367 \\
\hline 34 & 0.0202862 & 0.0025369 & 0.0005178 & 0.0226464 & 0.0072757 & 0.0032367 \\
\hline 36 & 0.0202862 & 0.0025369 & 0.0005178 & 0.0226464 & 0.0072757 & 0.0032367 \\
\hline 38 & 0.0202862 & 0.0025369 & 0.0005178 & 0.0226465 & 0.0072757 & 0.0032367 \\
\hline 40 & 0.0202863 & 0.0025369 & 0.0005178 & 0.0226465 & 0.0072757 & 0.0032367 \\
\hline 100 & 0.0202864 & 0.0025369 & 0.0005178 & 0.0226469 & 0.0072758 & 0.0032367 \\
\hline 400 & 0.0202865 & 0.0025369 & 0.0005178 & 0.0226471 & 0.0072758 & 0.0032367 \\
\hline
\end{tabular}


Table A4. Nondimensional central deflection of $(C)$ super-elliptical plates $(p=26, \eta=0.050)$

\begin{tabular}{|l|l|l|l|l|l|l|}
\hline & $\mathrm{W}$ & $\mathrm{W}$ & $\mathrm{W}$ & $\lambda$ & $\lambda$ & $\lambda$ \\
\hline $2 \mathrm{k}$ & $\mathrm{c}=1$ & $\mathrm{c}=2$ & $\mathrm{c}=3$ & $\mathrm{c}=1$ & $\mathrm{c}=2$ & $\mathrm{c}=3$ \\
\hline 2 & 0.0157985 & 0.0021374 & 0.0004776 & 0.0210805 & 0.007135 & 0.0032692 \\
\hline 4 & 0.0199967 & 0.002511 & 0.0005188 & 0.0234863 & 0.0075038 & 0.0033422 \\
\hline 6 & 0.0203998 & 0.0025472 & 0.0005212 & 0.023674 & 0.0075277 & 0.0033453 \\
\hline 8 & 0.0204702 & 0.0025535 & 0.0005215 & 0.0237062 & 0.0075316 & 0.0033459 \\
\hline 10 & 0.0204879 & 0.0025551 & 0.0005215 & 0.0237155 & 0.0075329 & 0.0033461 \\
\hline 12 & 0.0204934 & 0.0025556 & 0.0005216 & 0.0237195 & 0.0075335 & 0.0033463 \\
\hline 14 & 0.0204955 & 0.0025558 & 0.0005216 & 0.0237218 & 0.0075338 & 0.0033464 \\
\hline 16 & 0.0204964 & 0.0025559 & 0.0005215 & 0.0237232 & 0.0075341 & 0.0033465 \\
\hline 18 & 0.0204968 & 0.0025559 & 0.0005215 & 0.0237243 & 0.0075343 & 0.0033465 \\
\hline 20 & 0.0204971 & 0.0025559 & 0.0005215 & 0.0237251 & 0.0075344 & 0.0033466 \\
\hline 22 & 0.0204972 & 0.002556 & 0.0005215 & 0.0237258 & 0.0075346 & 0.0033466 \\
\hline 24 & 0.0204973 & 0.002556 & 0.0005215 & 0.0237264 & 0.0075347 & 0.0033467 \\
\hline 26 & 0.0204974 & 0.002556 & 0.0005215 & 0.0237268 & 0.0075347 & 0.0033467 \\
\hline 28 & 0.0204974 & 0.002556 & 0.0005215 & 0.0237272 & 0.0075348 & 0.0033467 \\
\hline 30 & 0.0204974 & 0.002556 & 0.0005215 & 0.0237276 & 0.0075349 & 0.0033467 \\
\hline 32 & 0.0204975 & 0.002556 & 0.0005215 & 0.0237279 & 0.0075349 & 0.0033467 \\
\hline 34 & 0.0204975 & 0.002556 & 0.0005215 & 0.0237282 & 0.007535 & 0.0033467 \\
\hline 36 & 0.0204975 & 0.002556 & 0.0005215 & 0.0237284 & 0.007535 & 0.0033468 \\
\hline 38 & 0.0204975 & 0.002556 & 0.0005215 & 0.0237286 & 0.0075351 & 0.0033468 \\
\hline 40 & 0.0204975 & 0.002556 & 0.0005215 & 0.0237288 & 0.0075351 & 0.0033468 \\
\hline 100 & 0.0204977 & 0.002556 & 0.0005215 & 0.0237311 & 0.0075355 & 0.0033469 \\
\hline 400 & 0.0204978 & 0.002556 & 0.0005215 & 0.0237324 & 0.0075357 & 0.003347 \\
\hline
\end{tabular}

Table A5. Nondimensional central deflection of $(C)$ super-elliptical plates $(p=26, \eta=0.100)$

\begin{tabular}{|l|l|l|l|l|l|l|}
\hline & $\mathrm{W}$ & $\mathrm{W}$ & $\mathrm{W}$ & $\lambda$ & $\lambda$ & $\lambda$ \\
\hline $2 \mathrm{k}$ & $\mathrm{c}=1$ & $\mathrm{c}=2$ & $\mathrm{c}=3$ & $\mathrm{c}=1$ & $\mathrm{c}=2$ & $\mathrm{c}=3$ \\
\hline 2 & 0.0163341 & 0.002195 & 0.0004902 & 0.0246689 & 0.0080081 & 0.0036407 \\
\hline 4 & 0.0206759 & 0.0025769 & 0.0005322 & 0.0272251 & 0.0084088 & 0.0037277 \\
\hline 6 & 0.0211185 & 0.0026145 & 0.0005347 & 0.027463 & 0.008441 & 0.003734 \\
\hline 8 & 0.021201 & 0.0026212 & 0.0005349 & 0.0275167 & 0.0084486 & 0.0037359 \\
\hline 10 & 0.0212231 & 0.0026229 & 0.0005350 & 0.0275379 & 0.008452 & 0.0037369 \\
\hline 12 & 0.0212306 & 0.0026235 & 0.0005350 & 0.0275494 & 0.0084539 & 0.0037375 \\
\hline 14 & 0.0212337 & 0.0026237 & 0.0005350 & 0.0275568 & 0.0084553 & 0.0037379 \\
\hline 16 & 0.0212351 & 0.0026238 & 0.0005350 & 0.0275622 & 0.0084563 & 0.0037382 \\
\hline 18 & 0.0212358 & 0.0026238 & 0.0005350 & 0.0275662 & 0.008457 & 0.0037385 \\
\hline 20 & 0.0212362 & 0.0026238 & 0.0005350 & 0.0275694 & 0.0084576 & 0.0037387 \\
\hline 22 & 0.0212365 & 0.0026239 & 0.0005350 & 0.027572 & 0.0084581 & 0.0037388 \\
\hline 24 & 0.0212366 & 0.0026239 & 0.0005350 & 0.0275742 & 0.0084585 & 0.003739 \\
\hline
\end{tabular}


Table A5. Nondimensional central deflection of $(C)$ super-elliptical plates $(p=26, \eta=0.100)$ (continue)

\begin{tabular}{|l|l|l|l|l|l|l|}
\hline & $\mathrm{W}$ & $\mathrm{W}$ & $\mathrm{W}$ & $\lambda$ & $\lambda$ & $\lambda$ \\
\hline $2 \mathrm{k}$ & $\mathrm{c}=1$ & $\mathrm{c}=2$ & $\mathrm{c}=3$ & $\mathrm{c}=1$ & $\mathrm{c}=2$ & $\mathrm{c}=3$ \\
\hline 26 & 0.0212367 & 0.0026239 & 0.0005350 & 0.0275761 & 0.0084588 & 0.0037391 \\
\hline 28 & 0.0212368 & 0.0026239 & 0.0005350 & 0.0275776 & 0.0084591 & 0.0037392 \\
\hline 30 & 0.0212369 & 0.0026239 & 0.0005350 & 0.027579 & 0.0084593 & 0.0037393 \\
\hline 32 & 0.0212369 & 0.0026239 & 0.0005350 & 0.0275802 & 0.0084596 & 0.0037393 \\
\hline 34 & 0.021237 & 0.0026239 & 0.0005350 & 0.0275812 & 0.0084598 & 0.0037394 \\
\hline 36 & 0.021237 & 0.0026239 & 0.0005350 & 0.0275822 & 0.0084599 & 0.0037394 \\
\hline 38 & 0.021237 & 0.0026239 & 0.0005350 & 0.027583 & 0.0084601 & 0.0037395 \\
\hline 40 & 0.021237 & 0.0026239 & 0.0005350 & 0.0275838 & 0.0084602 & 0.0037395 \\
\hline 100 & 0.0212372 & 0.0026239 & 0.0005350 & 0.0275928 & 0.0084617 & 0.003740 \\
\hline 400 & 0.0212373 & 0.0026239 & 0.0005350 & 0.0275979 & 0.0084627 & 0.0037403 \\
\hline
\end{tabular}

Table A6. Nondimensional central deflection of $(S)$ super-elliptical plates $(p=26, \eta=0.002)$

\begin{tabular}{|l|l|l|l|l|l|l|l|l|}
\hline & $\mathrm{W}$ & $\mathrm{W}$ & $\mathrm{W}$ & $\mathrm{W}$ & $\lambda$ & $\lambda$ & $\lambda$ & $\lambda$ \\
\hline $2 \mathrm{k}$ & $\mathrm{c}=1$ & $\mathrm{c}=2$ & $\mathrm{c}=3$ & $\mathrm{c}=5$ & $\mathrm{c}=1$ & $\mathrm{c}=2$ & $\mathrm{c}=3$ & $\mathrm{c}=5$ \\
\hline 2 & 0.0636745 & 0.008894 & 0.0021009 & 0.0003069 & 0.0504901 & 0.0165024 & 0.0074299 & 0.0026975 \\
\hline 4 & 0.0729315 & 0.0105591 & 0.0024185 & 0.0003301 & 0.0514505 & 0.0170786 & 0.0075629 & 0.0027121 \\
\hline 6 & 0.0702026 & 0.0104952 & 0.0024387 & 0.0003319 & 0.0493006 & 0.0168586 & 0.0075473 & 0.0027114 \\
\hline 8 & 0.0684491 & 0.0103899 & 0.0024357 & 0.0003322 & 0.048222 & 0.016735 & 0.0075382 & 0.0027111 \\
\hline 10 & 0.0674217 & 0.0103182 & 0.0024315 & 0.0003322 & 0.0476429 & 0.0166673 & 0.0075333 & 0.002711 \\
\hline 12 & 0.0667878 & 0.0102711 & 0.0024282 & 0.0003322 & 0.0473018 & 0.0166272 & 0.0075306 & 0.002711 \\
\hline 14 & 0.0663739 & 0.0102393 & 0.0024258 & 0.0003322 & 0.0470854 & 0.0166018 & 0.0075289 & 0.0027109 \\
\hline 16 & 0.0660904 & 0.0102171 & 0.0024241 & 0.0003322 & 0.0469402 & 0.0165847 & 0.0075277 & 0.0027109 \\
\hline 18 & 0.0658883 & 0.0102011 & 0.0024228 & 0.0003322 & 0.0468381 & 0.0165727 & 0.0075269 & 0.0027109 \\
\hline 20 & 0.0657395 & 0.0101892 & 0.0024218 & 0.0003322 & 0.0467637 & 0.016564 & 0.0075264 & 0.0027109 \\
\hline 22 & 0.0656269 & 0.0101801 & 0.0024211 & 0.0003322 & 0.0467079 & 0.0165574 & 0.0075259 & 0.0027108 \\
\hline 24 & 0.0655398 & 0.010173 & 0.0024205 & 0.0003322 & 0.0466649 & 0.0165524 & 0.0075256 & 0.0027108 \\
\hline 26 & 0.0654709 & 0.0101674 & 0.002420 & 0.0003322 & 0.0466312 & 0.0165485 & 0.0075254 & 0.0027108 \\
\hline 28 & 0.0654157 & 0.0101629 & 0.0024196 & 0.0003322 & 0.0466043 & 0.0165453 & 0.0075252 & 0.0027108 \\
\hline 30 & 0.0653707 & 0.0101592 & 0.0024193 & 0.0003322 & 0.0465824 & 0.0165427 & 0.007525 & 0.0027108 \\
\hline 32 & 0.0653335 & 0.0101561 & 0.002419 & 0.0003322 & 0.0465644 & 0.0165406 & 0.0075248 & 0.0027108 \\
\hline 34 & 0.0653025 & 0.0101536 & 0.0024188 & 0.0003322 & 0.0465494 & 0.0165389 & 0.0075247 & 0.0027108 \\
\hline 36 & 0.0652763 & 0.0101514 & 0.0024186 & 0.0003322 & 0.0465368 & 0.0165374 & 0.0075246 & 0.0027108 \\
\hline 38 & 0.0652541 & 0.0101496 & 0.0024185 & 0.0003322 & 0.0465261 & 0.0165362 & 0.0075246 & 0.0027108 \\
\hline 40 & 0.065235 & 0.010148 & 0.0024183 & 0.0003322 & 0.0465169 & 0.0165351 & 0.0075245 & 0.0027108 \\
\hline 100 & 0.0650823 & 0.0101352 & 0.0024172 & 0.0003321 & 0.046444 & 0.0165265 & 0.0075239 & 0.0027108 \\
\hline 400 & 0.0650483 & 0.0101323 & 0.002417 & 0.0003321 & 0.0464279 & 0.0165246 & 0.0075238 & 0.0027108 \\
\hline & & & & & & & & \\
\hline
\end{tabular}


Table A7. Nondimensional central deflection of (S) super-elliptical plates $(p=26, \eta=0.010)$

\begin{tabular}{|l|l|l|l|l|l|l|l|l|}
\hline & $\mathrm{W}$ & $\mathrm{W}$ & $\mathrm{W}$ & $\mathrm{W}$ & $\lambda$ & $\lambda$ & $\lambda$ & $\lambda$ \\
\hline $2 \mathrm{k}$ & $\mathrm{c}=1$ & $\mathrm{c}=2$ & $\mathrm{c}=3$ & $\mathrm{c}=5$ & $\mathrm{c}=1$ & $\mathrm{c}=2$ & $\mathrm{c}=3$ & $\mathrm{c}=5$ \\
\hline 2 & 0.0636814 & 0.0088986 & 0.002102 & 0.0003070 & 0.0505361 & 0.0165219 & 0.0074394 & 0.002701 \\
\hline 4 & 0.0730054 & 0.0105663 & 0.0024195 & 0.0003301 & 0.0515375 & 0.0171014 & 0.0075729 & 0.0027157 \\
\hline 6 & 0.0703163 & 0.0105047 & 0.0024398 & 0.0003320 & 0.0494094 & 0.0168836 & 0.0075575 & 0.0027149 \\
\hline 8 & 0.0685856 & 0.0104007 & 0.0024369 & 0.0003323 & 0.0483427 & 0.0167611 & 0.0075484 & 0.0027147 \\
\hline 10 & 0.0675735 & 0.0103299 & 0.0024328 & 0.0003323 & 0.0477714 & 0.0166941 & 0.0075437 & 0.0027146 \\
\hline 12 & 0.0669505 & 0.0102835 & 0.0024296 & 0.0003323 & 0.0474359 & 0.0166546 & 0.0075409 & 0.0027145 \\
\hline 14 & 0.066545 & 0.0102523 & 0.0024273 & 0.0003323 & 0.0472238 & 0.0166295 & 0.0075392 & 0.0027145 \\
\hline 16 & 0.0662681 & 0.0102305 & 0.0024255 & 0.0003323 & 0.0470818 & 0.0166128 & 0.0075381 & 0.0027145 \\
\hline 18 & 0.0660714 & 0.0102148 & 0.0024243 & 0.0003323 & 0.0469823 & 0.016601 & 0.0075374 & 0.0027144 \\
\hline 20 & 0.0659271 & 0.0102031 & 0.0024233 & 0.0003322 & 0.0469101 & 0.0165925 & 0.0075368 & 0.0027144 \\
\hline 22 & 0.0658182 & 0.0101942 & 0.0024226 & 0.0003322 & 0.0468562 & 0.0165861 & 0.0075364 & 0.0027144 \\
\hline 24 & 0.0657343 & 0.0101874 & 0.002422 & 0.0003322 & 0.0468148 & 0.0165812 & 0.0075361 & 0.0027144 \\
\hline 26 & 0.0656682 & 0.0101819 & 0.0024216 & 0.0003322 & 0.0467824 & 0.0165774 & 0.0075358 & 0.0027144 \\
\hline 28 & 0.0656154 & 0.0101775 & 0.0024212 & 0.0003322 & 0.0467566 & 0.0165743 & 0.0075356 & 0.0027144 \\
\hline 30 & 0.0655725 & 0.010174 & 0.0024209 & 0.0003322 & 0.0467358 & 0.0165719 & 0.0075355 & 0.0027144 \\
\hline 32 & 0.0655372 & 0.010171 & 0.0024206 & 0.0003322 & 0.0467187 & 0.0165699 & 0.0075353 & 0.0027144 \\
\hline 34 & 0.0655078 & 0.0101686 & 0.0024204 & 0.0003322 & 0.0467045 & 0.0165682 & 0.0075352 & 0.0027144 \\
\hline 36 & 0.0654832 & 0.0101665 & 0.0024202 & 0.0003322 & 0.0466926 & 0.0165668 & 0.0075352 & 0.0027144 \\
\hline 38 & 0.0654623 & 0.0101647 & 0.0024201 & 0.0003322 & 0.0466825 & 0.0165656 & 0.0075351 & 0.0027144 \\
\hline 40 & 0.0654444 & 0.0101632 & 0.0024199 & 0.0003322 & 0.046674 & 0.0165645 & 0.007535 & 0.0027144 \\
\hline 100 & 0.0653053 & 0.0101513 & 0.0024189 & 0.0003322 & 0.0466076 & 0.0165566 & 0.0075345 & 0.0027143 \\
\hline 400 & 0.0652761 & 0.0101487 & 0.0024187 & 0.0003322 & 0.0465938 & 0.0165548 & 0.0075344 & 0.0027143 \\
\hline
\end{tabular}

Table A8. Nondimensional central deflection of $(S)$ super-elliptical plates $(p=26, \eta=0.020)$

\begin{tabular}{|l|l|l|l|l|l|l|l|l|}
\hline & $\mathrm{W}$ & $\mathrm{W}$ & $\mathrm{W}$ & $\mathrm{W}$ & $\lambda$ & $\lambda$ & $\lambda$ & $\lambda$ \\
\hline $2 \mathrm{k}$ & $\mathrm{c}=1$ & $\mathrm{c}=2$ & $\mathrm{c}=3$ & $\mathrm{c}=5$ & $\mathrm{c}=1$ & $\mathrm{c}=2$ & $\mathrm{c}=3$ & $\mathrm{c}=5$ \\
\hline 2 & 0.0637028 & 0.0089057 & 0.0021037 & 0.0003072 & 0.0506796 & 0.0165669 & 0.007460 & 0.0027082 \\
\hline 4 & 0.0731182 & 0.010577 & 0.0024212 & 0.0003302 & 0.0517381 & 0.0171516 & 0.0075944 & 0.0027232 \\
\hline 6 & 0.0704814 & 0.0105183 & 0.0024416 & 0.0003321 & 0.0496391 & 0.0169366 & 0.0075793 & 0.0027225 \\
\hline 8 & 0.0687806 & 0.0104162 & 0.0024389 & 0.0003324 & 0.0485882 & 0.0168157 & 0.0075704 & 0.0027222 \\
\hline 10 & 0.0677882 & 0.0103466 & 0.0024348 & 0.0003324 & 0.0480272 & 0.0167497 & 0.0075658 & 0.0027221 \\
\hline 12 & 0.0671794 & 0.010301 & 0.0024317 & 0.0003324 & 0.0476989 & 0.0167109 & 0.0075631 & 0.0027221 \\
\hline 14 & 0.0667846 & 0.0102705 & 0.0024294 & 0.0003324 & 0.0474922 & 0.0166863 & 0.0075615 & 0.0027221 \\
\hline 16 & 0.066516 & 0.0102492 & 0.0024277 & 0.0003324 & 0.0473544 & 0.01667 & 0.0075604 & 0.002722 \\
\hline 18 & 0.0663261 & 0.0102339 & 0.0024265 & 0.0003324 & 0.0472584 & 0.0166585 & 0.0075597 & 0.002722 \\
\hline 20 & 0.0661872 & 0.0102225 & 0.0024256 & 0.0003323 & 0.0471889 & 0.0166503 & 0.0075591 & 0.002722 \\
\hline 22 & 0.066083 & 0.010214 & 0.0024249 & 0.0003323 & 0.0471372 & 0.0166441 & 0.0075587 & 0.002722 \\
\hline 24 & 0.0660029 & 0.0102073 & 0.0024243 & 0.0003323 & 0.0470978 & 0.0166394 & 0.0075584 & 0.002722 \\
\hline 26 & 0.0659401 & 0.0102021 & 0.0024239 & 0.0003323 & 0.0470671 & 0.0166357 & 0.0075582 & 0.002722 \\
\hline 28 & 0.0658901 & 0.0101979 & 0.0024235 & 0.0003323 & 0.0470427 & 0.0166328 & 0.007558 & 0.002722 \\
\hline 30 & 0.0658497 & 0.0101945 & 0.0024232 & 0.0003323 & 0.0470231 & 0.0166304 & 0.0075578 & 0.002722 \\
\hline 32 & 0.0658166 & 0.0101916 & 0.002423 & 0.0003323 & 0.047007 & 0.0166285 & 0.0075577 & 0.002722 \\
\hline 34 & 0.0657891 & 0.0101893 & 0.0024228 & 0.0003323 & 0.0469938 & 0.0166269 & 0.0075576 & 0.002722 \\
\hline 36 & 0.0657662 & 0.0101873 & 0.0024226 & 0.0003323 & 0.0469827 & 0.0166255 & 0.0075575 & 0.002722 \\
\hline 38 & 0.0657467 & 0.0101857 & 0.0024224 & 0.0003323 & 0.0469734 & 0.0166244 & 0.0075575 & 0.002722 \\
\hline 40 & 0.0657302 & 0.0101842 & 0.0024223 & 0.0003323 & 0.0469655 & 0.0166234 & 0.0075574 & 0.002722 \\
\hline 100 & 0.0656044 & 0.0101732 & 0.0024213 & 0.0003323 & 0.0469057 & 0.0166161 & 0.0075569 & 0.0027219 \\
\hline 400 & 0.0655787 & 0.0101708 & 0.0024211 & 0.0003323 & 0.0468937 & 0.0166146 & 0.0075568 & 0.0027219 \\
\hline & & & & & & & & \\
\hline
\end{tabular}


Table A9. Nondimensional central deflection of (S) super-elliptical plates $(p=26, \eta=0.050)$

\begin{tabular}{|l|l|l|l|l|l|l|l|l|}
\hline & $\mathrm{W}$ & $\mathrm{W}$ & $\mathrm{W}$ & $\mathrm{W}$ & $\lambda$ & $\lambda$ & $\lambda$ & $\lambda$ \\
\hline $2 \mathrm{k}$ & $\mathrm{c}=1$ & $\mathrm{c}=2$ & $\mathrm{c}=3$ & $\mathrm{c}=5$ & $\mathrm{c}=1$ & $\mathrm{c}=2$ & $\mathrm{c}=3$ & $\mathrm{c}=5$ \\
\hline 2 & 0.0638528 & 0.0089362 & 0.0021108 & 0.0003079 & 0.0516844 & 0.01684 & 0.0075802 & 0.0027496 \\
\hline 4 & 0.0735879 & 0.0106203 & 0.0024283 & 0.0003308 & 0.0529488 & 0.0174451 & 0.0077195 & 0.0027663 \\
\hline 6 & 0.0711233 & 0.0105711 & 0.0024492 & 0.0003327 & 0.0509485 & 0.0172402 & 0.0077058 & 0.0027658 \\
\hline 8 & 0.0695174 & 0.0104746 & 0.0024469 & 0.0003329 & 0.0499498 & 0.0171247 & 0.0076976 & 0.0027657 \\
\hline 10 & 0.0685858 & 0.0104087 & 0.0024431 & 0.0003330 & 0.0494214 & 0.0170621 & 0.0076934 & 0.0027657 \\
\hline 12 & 0.0680194 & 0.0103658 & 0.0024402 & 0.0003330 & 0.0491157 & 0.0170255 & 0.007691 & 0.0027657 \\
\hline 14 & 0.0676557 & 0.0103372 & 0.002438 & 0.0003329 & 0.0489254 & 0.0170026 & 0.0076895 & 0.0027657 \\
\hline 16 & 0.0674107 & 0.0103174 & 0.0024365 & 0.0003329 & 0.04880 & 0.0169875 & 0.0076886 & 0.0027657 \\
\hline 18 & 0.0672392 & 0.0103032 & 0.0024353 & 0.0003329 & 0.0487136 & 0.0169771 & 0.0076879 & 0.0027657 \\
\hline 20 & 0.067115 & 0.0102929 & 0.0024345 & 0.0003329 & 0.0486518 & 0.0169696 & 0.0076875 & 0.0027657 \\
\hline 22 & 0.0670225 & 0.010285 & 0.0024338 & 0.0003329 & 0.0486064 & 0.016964 & 0.0076871 & 0.0027657 \\
\hline 24 & 0.0669521 & 0.010279 & 0.0024333 & 0.0003329 & 0.048572 & 0.0169598 & 0.0076869 & 0.0027657 \\
\hline 26 & 0.0668974 & 0.0102743 & 0.0024329 & 0.0003329 & 0.0485455 & 0.0169566 & 0.0076867 & 0.0027657 \\
\hline 28 & 0.0668542 & 0.0102706 & 0.0024326 & 0.0003329 & 0.0485246 & 0.016954 & 0.0076865 & 0.0027657 \\
\hline 30 & 0.0668194 & 0.0102675 & 0.0024323 & 0.0003329 & 0.048508 & 0.016952 & 0.0076864 & 0.0027657 \\
\hline 32 & 0.0667911 & 0.010265 & 0.0024321 & 0.0003329 & 0.0484945 & 0.0169503 & 0.0076863 & 0.0027657 \\
\hline 34 & 0.0667678 & 0.010263 & 0.0024319 & 0.0003329 & 0.0484834 & 0.0169489 & 0.0076863 & 0.0027657 \\
\hline 36 & 0.0667484 & 0.0102613 & 0.0024318 & 0.0003329 & 0.0484743 & 0.0169478 & 0.0076862 & 0.0027657 \\
\hline 38 & 0.0667321 & 0.0102598 & 0.0024317 & 0.0003329 & 0.0484666 & 0.0169468 & 0.0076861 & 0.0027657 \\
\hline 40 & 0.0667183 & 0.0102586 & 0.0024315 & 0.0003329 & 0.0484601 & 0.016946 & 0.0076861 & 0.0027657 \\
\hline 100 & 0.0666152 & 0.0102492 & 0.0024307 & 0.0003329 & 0.048413 & 0.0169401 & 0.0076858 & 0.0027657 \\
\hline 400 & 0.0665933 & 0.0102472 & 0.0024305 & 0.0003329 & 0.0484038 & 0.016939 & 0.0076857 & 0.0027657 \\
\hline
\end{tabular}

Table A10. Nondimensional central deflection of (S) super-elliptical plates $(p=26, \eta=0.100)$

\begin{tabular}{|l|l|l|l|l|l|l|l|l|}
\hline & $\mathrm{W}$ & $\mathrm{W}$ & $\mathrm{W}$ & $\mathrm{W}$ & $\lambda$ & $\lambda$ & $\lambda$ & $\lambda$ \\
\hline $2 \mathrm{k}$ & $\mathrm{c}=1$ & $\mathrm{c}=2$ & $\mathrm{c}=3$ & $\mathrm{c}=5$ & $\mathrm{c}=1$ & $\mathrm{c}=2$ & $\mathrm{c}=3$ & $\mathrm{c}=5$ \\
\hline 2 & 0.0643885 & 0.009017 & 0.002129 & 0.0003101 & 0.0552728 & 0.017755 & 0.0079749 & 0.0028843 \\
\hline 4 & 0.0747886 & 0.010729 & 0.0024473 & 0.0003328 & 0.0569857 & 0.0184107 & 0.0081293 & 0.0029066 \\
\hline 6 & 0.0726465 & 0.0106973 & 0.0024692 & 0.0003345 & 0.0551806 & 0.0182273 & 0.0081196 & 0.0029072 \\
\hline 8 & 0.071204 & 0.0106105 & 0.0024675 & 0.0003348 & 0.054278 & 0.0181226 & 0.0081132 & 0.0029074 \\
\hline 10 & 0.0703689 & 0.0105507 & 0.0024642 & 0.0003348 & 0.0538061 & 0.0180664 & 0.008110 & 0.0029076 \\
\hline 12 & 0.0698649 & 0.0105118 & 0.0024615 & 0.0003348 & 0.0535368 & 0.018034 & 0.0081083 & 0.0029077 \\
\hline 14 & 0.0695437 & 0.010486 & 0.0024596 & 0.0003348 & 0.0533716 & 0.0180141 & 0.0081073 & 0.0029078 \\
\hline 16 & 0.069329 & 0.0104683 & 0.0024582 & 0.0003348 & 0.0532641 & 0.0180011 & 0.0081067 & 0.0029079 \\
\hline 18 & 0.0691795 & 0.0104557 & 0.0024572 & 0.0003348 & 0.053191 & 0.0179923 & 0.0081063 & 0.0029079 \\
\hline 20 & 0.0690719 & 0.0104466 & 0.0024565 & 0.0003348 & 0.0531394 & 0.0179861 & 0.008106 & 0.002908 \\
\hline 22 & 0.0689921 & 0.0104397 & 0.0024559 & 0.0003348 & 0.0531018 & 0.0179815 & 0.0081058 & 0.002908 \\
\hline 24 & 0.0689316 & 0.0104344 & 0.0024555 & 0.0003348 & 0.0530736 & 0.0179781 & 0.0081057 & 0.002908 \\
\hline 26 & 0.0688847 & 0.0104303 & 0.0024551 & 0.0003348 & 0.0530521 & 0.0179755 & 0.0081056 & 0.002908 \\
\hline 28 & 0.0688476 & 0.010427 & 0.0024548 & 0.0003348 & 0.0530353 & 0.0179735 & 0.0081056 & 0.0029081 \\
\hline 30 & 0.0688179 & 0.0104244 & 0.0024546 & 0.0003348 & 0.0530221 & 0.0179719 & 0.0081055 & 0.0029081 \\
\hline 32 & 0.0687938 & 0.0104223 & 0.0024544 & 0.0003348 & 0.0530114 & 0.0179707 & 0.0081055 & 0.0029081 \\
\hline 34 & 0.0687739 & 0.0104205 & 0.0024542 & 0.0003348 & 0.0530027 & 0.0179696 & 0.0081055 & 0.0029081 \\
\hline 36 & 0.0687573 & 0.010419 & 0.0024541 & 0.0003348 & 0.0529956 & 0.0179688 & 0.0081055 & 0.0029081 \\
\hline 38 & 0.0687434 & 0.0104177 & 0.002454 & 0.0003348 & 0.0529896 & 0.0179681 & 0.0081055 & 0.0029081 \\
\hline 40 & 0.0687316 & 0.0104167 & 0.0024539 & 0.0003348 & 0.0529846 & 0.0179675 & 0.0081055 & 0.0029081 \\
\hline 100 & 0.0686419 & 0.0104086 & 0.0024531 & 0.0003348 & 0.0529503 & 0.0179636 & 0.0081055 & 0.0029082 \\
\hline 400 & 0.0686209 & 0.0104068 & 0.002453 & 0.0003348 & 0.0529454 & 0.0179633 & 0.0081057 & 0.0029083 \\
\hline
\end{tabular}


Table A11. Nondimensional central deflection of (PS) super-elliptical plates $(p=38, \eta=0.002)$

\begin{tabular}{|l|l|l|l|l|l|l|}
\hline & $\mathrm{W}$ & $\mathrm{W}$ & $\mathrm{W}$ & $\lambda$ & $\lambda$ & $\lambda$ \\
\hline $2 \mathrm{k}$ & $\mathrm{c}=1$ & $\mathrm{c}=2$ & $\mathrm{c}=3$ & $\mathrm{c}=1$ & $\mathrm{c}=2$ & $\mathrm{c}=3$ \\
\hline 2 & 0.0828439 & 0.0496860 & 0.0498087 & 0.0567861 & 0.0650117 & 0.0965172 \\
\hline 4 & 0.180261 & 0.107651 & 0.107750 & 0.0900652 & 0.105834 & 0.158468 \\
\hline 6 & 0.234681 & 0.138874 & 0.138519 & 0.106860 & 0.125763 & 0.188297 \\
\hline 8 & 0.268146 & 0.157613 & 0.156803 & 0.116866 & 0.137362 & 0.205496 \\
\hline 10 & 0.290677 & 0.170016 & 0.168817 & 0.123500 & 0.144927 & 0.216637 \\
\hline 12 & 0.306864 & 0.178814 & 0.177292 & 0.128222 & 0.150247 & 0.224432 \\
\hline 14 & 0.319056 & 0.185377 & 0.183586 & 0.131756 & 0.154192 & 0.230189 \\
\hline 16 & 0.328572 & 0.190458 & 0.188441 & 0.134503 & 0.157234 & 0.234613 \\
\hline 18 & 0.336207 & 0.194510 & 0.192301 & 0.136699 & 0.159652 & 0.238120 \\
\hline 20 & 0.342471 & 0.197816 & 0.195442 & 0.138496 & 0.161620 & 0.240968 \\
\hline 22 & 0.347704 & 0.200565 & 0.198049 & 0.139994 & 0.163254 & 0.243327 \\
\hline 24 & 0.352142 & 0.202888 & 0.200246 & 0.141262 & 0.164631 & 0.245313 \\
\hline 26 & 0.355953 & 0.204875 & 0.202124 & 0.142349 & 0.165808 & 0.247007 \\
\hline 28 & 0.359263 & 0.206596 & 0.203747 & 0.143293 & 0.166826 & 0.248471 \\
\hline 30 & 0.362163 & 0.208100 & 0.205164 & 0.144118 & 0.167716 & 0.249747 \\
\hline 32 & 0.364727 & 0.209426 & 0.206412 & 0.144847 & 0.168499 & 0.250870 \\
\hline 34 & 0.367010 & 0.210605 & 0.207519 & 0.145496 & 0.169194 & 0.251865 \\
\hline 36 & 0.369055 & 0.211658 & 0.208508 & 0.146077 & 0.169815 & 0.252754 \\
\hline 38 & 0.370898 & 0.212606 & 0.209397 & 0.146600 & 0.170373 & 0.253553 \\
\hline 40 & 0.372567 & 0.213463 & 0.210200 & 0.147073 & 0.170878 & 0.254275 \\
\hline 100 & 0.392393 & 0.223530 & 0.219583 & 0.152677 & 0.176788 & 0.262675 \\
\hline 400 & 0.402925 & 0.228789 & 0.224440 & 0.155642 & 0.179862 & 0.267007 \\
\hline & & & & & & \\
\hline
\end{tabular}

Table A12. Nondimensional central deflection of (PS) super-elliptical plates $(p=38, \eta=0.010)$

\begin{tabular}{|l|l|l|l|l|l|l|}
\hline & $\mathrm{W}$ & $\mathrm{W}$ & $\mathrm{W}$ & $\lambda$ & $\lambda$ & $\lambda$ \\
\hline $2 \mathrm{k}$ & $\mathrm{c}=1$ & $\mathrm{c}=2$ & $\mathrm{c}=3$ & $\mathrm{c}=1$ & $\mathrm{c}=2$ & $\mathrm{c}=3$ \\
\hline 2 & 0.0829997 & 0.0497447 & 0.0498487 & 0.0568923 & 0.0650605 & 0.0965594 \\
\hline 4 & 0.180465 & 0.107733 & 0.107802 & 0.0901769 & 0.105890 & 0.158516 \\
\hline 6 & 0.234941 & 0.138966 & 0.138575 & 0.106984 & 0.125824 & 0.188348 \\
\hline 8 & 0.268461 & 0.157711 & 0.156859 & 0.117003 & 0.137427 & 0.205548 \\
\hline 10 & 0.291041 & 0.170118 & 0.168873 & 0.123649 & 0.144994 & 0.216689 \\
\hline 12 & 0.307270 & 0.178920 & 0.177348 & 0.128382 & 0.150316 & 0.224484 \\
\hline 14 & 0.319500 & 0.185485 & 0.183640 & 0.131926 & 0.154262 & 0.230240 \\
\hline 16 & 0.329048 & 0.190569 & 0.188495 & 0.134680 & 0.157305 & 0.234664 \\
\hline 18 & 0.336712 & 0.194622 & 0.192354 & 0.136884 & 0.159725 & 0.238170 \\
\hline 20 & 0.343002 & 0.197930 & 0.195495 & 0.138687 & 0.161694 & 0.241018 \\
\hline 22 & 0.348258 & 0.200681 & 0.198101 & 0.140191 & 0.163328 & 0.243376 \\
\hline
\end{tabular}


Table A12. Nondimensional central deflection of (PS) super-elliptical plates $(p=38, \eta=0.010)$ (continue)

\begin{tabular}{|l|l|l|l|l|l|l|}
\hline & $\mathrm{W}$ & $\mathrm{W}$ & $\mathrm{W}$ & $\lambda$ & $\lambda$ & $\lambda$ \\
\hline $2 \mathrm{k}$ & $\mathrm{c}=1$ & $\mathrm{c}=2$ & $\mathrm{c}=3$ & $\mathrm{c}=1$ & $\mathrm{c}=2$ & $\mathrm{c}=3$ \\
\hline 24 & 0.352716 & 0.203004 & 0.200298 & 0.141464 & 0.164706 & 0.245362 \\
\hline 26 & 0.356545 & 0.204994 & 0.202175 & 0.142556 & 0.165884 & 0.247056 \\
\hline 28 & 0.359871 & 0.206716 & 0.203798 & 0.143504 & 0.166903 & 0.248519 \\
\hline 30 & 0.362788 & 0.208221 & 0.205214 & 0.144333 & 0.167793 & 0.249795 \\
\hline 32 & 0.365365 & 0.209548 & 0.206462 & 0.145066 & 0.168577 & 0.250918 \\
\hline 34 & 0.367660 & 0.210728 & 0.207569 & 0.145718 & 0.169273 & 0.251914 \\
\hline 36 & 0.369717 & 0.211782 & 0.208558 & 0.146302 & 0.169894 & 0.252803 \\
\hline 38 & 0.371571 & 0.212731 & 0.209447 & 0.146827 & 0.170453 & 0.253602 \\
\hline 40 & 0.373250 & 0.213589 & 0.210250 & 0.147303 & 0.170959 & 0.254323 \\
\hline 100 & 0.393214 & 0.223675 & 0.219638 & 0.152944 & 0.176880 & 0.262729 \\
\hline 400 & 0.403840 & 0.228952 & 0.224505 & 0.155935 & 0.179965 & 0.267071 \\
\hline
\end{tabular}

Table A13. Nondimensional central deflection of (PS) super-elliptical plates $(p=38, \eta=0.020)$

\begin{tabular}{|l|l|l|l|l|l|l|}
\hline & $\mathrm{W}$ & $\mathrm{W}$ & $\mathrm{W}$ & $\lambda$ & $\lambda$ & $\lambda$ \\
\hline $2 \mathrm{k}$ & $\mathrm{c}=1$ & $\mathrm{c}=2$ & $\mathrm{c}=3$ & $\mathrm{c}=1$ & $\mathrm{c}=2$ & $\mathrm{c}=3$ \\
\hline 2 & 0.0832763 & 0.0498034 & 0.0498795 & 0.0571537 & 0.0651435 & 0.0966129 \\
\hline 4 & 0.180826 & 0.107809 & 0.107842 & 0.0904526 & 0.105978 & 0.158572 \\
\hline 6 & 0.235381 & 0.139054 & 0.138618 & 0.107279 & 0.125918 & 0.188407 \\
\hline 8 & 0.268975 & 0.157810 & 0.156906 & 0.117317 & 0.137526 & 0.205609 \\
\hline 10 & 0.291620 & 0.170227 & 0.168922 & 0.123980 & 0.145098 & 0.216753 \\
\hline 12 & 0.307907 & 0.179036 & 0.177398 & 0.128728 & 0.150424 & 0.224548 \\
\hline 14 & 0.320186 & 0.185608 & 0.183692 & 0.132285 & 0.154374 & 0.230306 \\
\hline 16 & 0.329778 & 0.190699 & 0.188548 & 0.135051 & 0.157421 & 0.234731 \\
\hline 18 & 0.337480 & 0.194758 & 0.192408 & 0.137264 & 0.159843 & 0.238238 \\
\hline 20 & 0.343803 & 0.198070 & 0.195550 & 0.139077 & 0.161815 & 0.241087 \\
\hline 22 & 0.349089 & 0.200826 & 0.198157 & 0.140589 & 0.163452 & 0.243446 \\
\hline 24 & 0.353573 & 0.203153 & 0.200355 & 0.141869 & 0.164832 & 0.245432 \\
\hline 26 & 0.357427 & 0.205146 & 0.202233 & 0.142968 & 0.166013 & 0.247127 \\
\hline 28 & 0.360775 & 0.206871 & 0.203857 & 0.143921 & 0.167033 & 0.248591 \\
\hline 30 & 0.363711 & 0.208380 & 0.205274 & 0.144756 & 0.167925 & 0.249868 \\
\hline 32 & 0.366306 & 0.209710 & 0.206522 & 0.145493 & 0.168710 & 0.250992 \\
\hline 34 & 0.368618 & 0.210892 & 0.207630 & 0.146150 & 0.169407 & 0.251988 \\
\hline 36 & 0.370690 & 0.211949 & 0.208620 & 0.146737 & 0.170030 & 0.252878 \\
\hline 38 & 0.372558 & 0.212900 & 0.209509 & 0.147267 & 0.170591 & 0.253677 \\
\hline 40 & 0.374251 & 0.213760 & 0.210313 & 0.147747 & 0.171097 & 0.254399 \\
\hline 100 & 0.394398 & 0.223877 & 0.219711 & 0.153439 & 0.177036 & 0.262814 \\
\hline 400 & 0.405156 & 0.229177 & 0.224587 & 0.156469 & 0.180135 & 0.267164 \\
\hline
\end{tabular}


Table A14. Nondimensional central deflection of (PS) super-elliptical plates $(p=38, \eta=0.050)$

\begin{tabular}{|l|l|l|l|l|l|l|}
\hline & $\mathrm{W}$ & $\mathrm{W}$ & $\mathrm{W}$ & $\lambda$ & $\lambda$ & $\lambda$ \\
\hline $2 \mathrm{k}$ & $\mathrm{c}=1$ & $\mathrm{c}=2$ & $\mathrm{c}=3$ & $\mathrm{c}=1$ & $\mathrm{c}=2$ & $\mathrm{c}=3$ \\
\hline 2 & 0.0846261 & 0.0500438 & 0.0499834 & 0.0587831 & 0.0656061 & 0.0968665 \\
\hline 4 & 0.182576 & 0.108113 & 0.107970 & 0.0921728 & 0.106465 & 0.158835 \\
\hline 6 & 0.237433 & 0.139403 & 0.138760 & 0.109082 & 0.126428 & 0.188681 \\
\hline 8 & 0.271287 & 0.158197 & 0.157059 & 0.119194 & 0.138058 & 0.205892 \\
\hline 10 & 0.294156 & 0.170647 & 0.169084 & 0.125921 & 0.145650 & 0.217044 \\
\hline 12 & 0.310634 & 0.179485 & 0.177568 & 0.130723 & 0.150992 & 0.224847 \\
\hline 14 & 0.323076 & 0.186082 & 0.183869 & 0.134327 & 0.154957 & 0.230611 \\
\hline 16 & 0.332810 & 0.191194 & 0.188732 & 0.137134 & 0.158017 & 0.235042 \\
\hline 18 & 0.340636 & 0.195273 & 0.192598 & 0.139383 & 0.160450 & 0.238554 \\
\hline 20 & 0.347068 & 0.198603 & 0.195745 & 0.141227 & 0.162432 & 0.241407 \\
\hline 22 & 0.352449 & 0.201373 & 0.198356 & 0.142767 & 0.164077 & 0.243770 \\
\hline 24 & 0.357020 & 0.203715 & 0.200559 & 0.144073 & 0.165466 & 0.245760 \\
\hline 26 & 0.360952 & 0.205720 & 0.202441 & 0.145194 & 0.166653 & 0.247459 \\
\hline 28 & 0.364370 & 0.207457 & 0.204068 & 0.146168 & 0.167680 & 0.248926 \\
\hline 30 & 0.367369 & 0.208976 & 0.205488 & 0.147022 & 0.168578 & 0.250206 \\
\hline 32 & 0.370023 & 0.210315 & 0.206740 & 0.147777 & 0.169369 & 0.251332 \\
\hline 34 & 0.372388 & 0.211506 & 0.207850 & 0.148449 & 0.170071 & 0.252331 \\
\hline 36 & 0.374510 & 0.212571 & 0.208842 & 0.149052 & 0.170699 & 0.253223 \\
\hline 38 & 0.376423 & 0.213529 & 0.209734 & 0.149595 & 0.171264 & 0.254024 \\
\hline 40 & 0.378159 & 0.214397 & 0.210540 & 0.150087 & 0.171775 & 0.254748 \\
\hline 100 & 0.398929 & 0.224617 & 0.219973 & 0.155971 & 0.177776 & 0.263196 \\
\hline 400 & 0.410184 & 0.230003 & 0.224883 & 0.159160 & 0.180932 & 0.267580 \\
\hline
\end{tabular}

Table A15. Nondimensional central deflection of (PS) super-elliptical plates $(p=38, \eta=0.100)$

\begin{tabular}{|l|l|l|l|l|l|l|}
\hline & $\mathrm{W}$ & $\mathrm{W}$ & $\mathrm{W}$ & $\lambda$ & $\lambda$ & $\lambda$ \\
\hline $2 \mathrm{k}$ & $\mathrm{c}=1$ & $\mathrm{c}=2$ & $\mathrm{c}=3$ & $\mathrm{c}=1$ & $\mathrm{c}=2$ & $\mathrm{c}=3$ \\
\hline 2 & 0.0885912 & 0.0506813 & 0.0502333 & 0.0643120 & 0.0670971 & 0.0976216 \\
\hline 4 & 0.187676 & 0.108918 & 0.108279 & 0.0980058 & 0.108040 & 0.159629 \\
\hline 6 & 0.243230 & 0.140307 & 0.139099 & 0.115132 & 0.128065 & 0.189502 \\
\hline 8 & 0.277631 & 0.159180 & 0.157421 & 0.125419 & 0.139745 & 0.206736 \\
\hline 10 & 0.300946 & 0.171696 & 0.169466 & 0.132289 & 0.147378 & 0.217907 \\
\hline 12 & 0.317795 & 0.180590 & 0.177967 & 0.137211 & 0.152757 & 0.225727 \\
\hline 14 & 0.330551 & 0.187235 & 0.184282 & 0.140918 & 0.156752 & 0.231505 \\
\hline 16 & 0.340554 & 0.192389 & 0.189157 & 0.143813 & 0.159838 & 0.235948 \\
\hline 18 & 0.348613 & 0.196503 & 0.193034 & 0.146139 & 0.162295 & 0.239471 \\
\hline 20 & 0.355251 & 0.199865 & 0.196191 & 0.148051 & 0.164297 & 0.242334 \\
\hline
\end{tabular}


Table A15. Nondimensional central deflection of (PS) super-elliptical plates $(p=38, \eta=0.100)$ (continue)

\begin{tabular}{|l|l|l|l|l|l|l|}
\hline & $\mathrm{W}$ & $\mathrm{W}$ & $\mathrm{W}$ & $\lambda$ & $\lambda$ & $\lambda$ \\
\hline $2 \mathrm{k}$ & $\mathrm{c}=1$ & $\mathrm{c}=2$ & $\mathrm{c}=3$ & $\mathrm{c}=1$ & $\mathrm{c}=2$ & $\mathrm{c}=3$ \\
\hline 22 & 0.360815 & 0.202664 & 0.198812 & 0.149651 & 0.165961 & 0.244706 \\
\hline 24 & 0.365549 & 0.205031 & 0.201022 & 0.151012 & 0.167366 & 0.246704 \\
\hline 26 & 0.369628 & 0.207060 & 0.202911 & 0.152182 & 0.168569 & 0.248410 \\
\hline 28 & 0.373180 & 0.208817 & 0.204545 & 0.153201 & 0.169610 & 0.249883 \\
\hline 30 & 0.376302 & 0.210355 & 0.205972 & 0.154097 & 0.170520 & 0.251169 \\
\hline 32 & 0.379069 & 0.211712 & 0.207228 & 0.154890 & 0.171323 & 0.252301 \\
\hline 34 & 0.381539 & 0.212919 & 0.208344 & 0.155598 & 0.172036 & 0.253305 \\
\hline 36 & 0.383758 & 0.213999 & 0.209341 & 0.156233 & 0.172674 & 0.254202 \\
\hline 38 & 0.385763 & 0.214972 & 0.210238 & 0.156808 & 0.173248 & 0.255008 \\
\hline 40 & 0.387583 & 0.215852 & 0.211048 & 0.157329 & 0.173768 & 0.255736 \\
\hline 100 & 0.409704 & 0.226284 & 0.220552 & 0.163679 & 0.179914 & 0.264261 \\
\hline 400 & 0.422200 & 0.231875 & 0.225540 & 0.167300 & 0.183214 & 0.268733 \\
\hline
\end{tabular}

